\title{
Plastids unleashed: their development and their integration in plant development
}

\author{
ENRIQUE LOPEZ-JUEZ ${ }^{*}, 1$ and KEVIN A. PYKE ${ }^{2}$ \\ ${ }^{1}$ School of Biological Sciences, Royal Holloway, University of London, Egham, Surrey, UK and ${ }^{2}$ Plant Sciences Division, School of \\ BioSciences, University of Nottingham, Sutton Bonnington Campus, Loughborough, UK
}

\begin{abstract}
Derived by endosymbiosis from ancestral cyanobacteria, chloroplasts integrated seamlessly into the biology of their host cell. That integration involved a massive transfer of genes to the cell's nucleus, with the modification of pre-existing processes, like plastid division and the operation of the plastid genetic machinery and the emergence of new ones, like the import of proteins translated in the cytoplasm. The uncovering in molecular detail of several of these processes reveals a merger of mechanisms of symbiont and host origin. Chloroplasts acquired roles as part of the biology of land plants by differentiating into a variety of interconvertible plastid forms according to the cell type. How these conversions take place, or how new problems, like the regulation of the plastid population size in cells, have been solved, is barely starting to be understood. Like the whole plant and as a result of the requirements and dangers associated with photosynthetic activity, chloroplasts in particular are under the control of environmental cues. Far from being passive targets of cellular processes, plastids are sources of signals of plastid-nuclear communication, which regulate activities for their own biogenesis. Plastids are also sources of developmental signals, in whose absence tissue architecture or cell differentiation are aberrant, in a cell-autonomous fashion. Over evolutionary time, plastids also contributed many genes for activities that are no longer directly associated with them (like light perception or hormone function). The overall picture is one in which plastids are at both the receiving and the acting ends in plant development, in both ontogenic and evolutionary terms.
\end{abstract}

KEY WORDS: chloroplast, plastid, photosynthesis, endosymbiotic, plastid-nuclear communication

\section{Introduction}

If there is one feature that distinguishes plant from animal life on our planet, it is not plants being primarily sessile or developing continuously through life, as a few animals share those; rather, it is the reliance of plants on solar energy to generate molecules with energy-rich bonds, the fuel that will be used by almost the entire biosphere (including plants themselves) to build other organised molecules and drive the rest of the processes that we know as life. Chloroplasts are the sites of this wonder-process. If an interstellar traveller arrived on our planet to analyse the organisms in it, it would probably eventually describe plants as 'living things that fix star photon energy in green corpuscles and produce organs that harbour those corpuscles exposed to light and air, in a protected environment, or bring water and other inorganic substances from the substrate to them'. Photosynthesis was an invention of several, seemingly very early prokaryotes, which eventually associated between themselves to exploit the inexhaustible resource, water, as the source of electrons energised by light (Blankenship 2001). Such oxygenic photosynthesis was the prerogative of cyanobacteria and it is now accepted beyond reasonable doubt that sometime over 1,000 million years ago, probably between 1,200 and 1,500, a single-cell, mitochondrioncontaining eukaryote, engulfed and established an endosymbiotic relationship with a cyanobacterium (Dyall et al., 2004). The green lineage among the descendants of this first photosynthetic eukaryote (there was a separate red lineage), eventually colonised the planet outside the oceans, around 450 million years ago (Willis and McElwain, 2002). By that time, in fact much earlier, the

\footnotetext{
Abbreviations used in this paper: GDP, guanosine diphosphate; GFP, green fluorescent protein; GTP, guanosine triphosphate; NEP, nuclear-encoded RNA polymerase; PEP, plastid-encoded RNA polymerase; POR, protochlorophyllide reductase; PS, photosystem; SRP, signal recognition particle; Tic, translocon of the inner membrane of chloroplast; Toc, translocon of the outer envelope of chloroplast.
} 
engulfed cyanobacteria had turned into what we know as chloroplasts. Chloroplasts retained a small degree of genetic autonomy, a large degree of their biochemistry, but lost some of their original functions and also acquired ones they did not possess when freeliving (Timmis et al., 2004). They needed to synthesise and accumulate their proteins, now produced in two separate compartments, within themselves and in their surrounding cytoplasm, locate them to their correct destination, divide and propagate because the cell they were in did and fill that cell to the right extent. The chloroplast's requirements to carry out photosynthesis would determine the land plant's development and its need to adapt such development to environmental signals, such as light or the availability of raw materials. The chloroplasts would also diversify into a variety of derivatives, that we now call other plastid types, to carry out other essential or specialised functions in other cells that were no-longer photosynthetic, or merely to be transmitted more easily and economically in young, embryonic or undifferentiated cells (Waters and Pyke, 2004). The chloroplasts or their derivatives would therefore become under the control of developmental signals that affected the cells harbouring them, or be influenced by the same environmental cues, to insure their function remained possible under a variety of conditions (Rodermel, 2001). As it is now apparent, the chloroplasts themselves would directly relay information to the nucleus of the cells in which they resided, on their own status or on environmental influences upon them, to integrate them fully into the biology of the cell or the organ (Surpin et al., 2002). Finally it is becoming increasingly clear that, as part of this integration, the chloroplasts accepted contributions from their original hosts, in order to build up the new processes that the endosymbiotic relationship required, but they also contributed extensively to the toolkit available to the host's genome in terms of biochemistry of secondary metabolism, or developmental or environmental perception mechanisms (Martin et al., 2002). This means that plants now possess a range of environmental sensors, small chemical regulators and morphogens, cellsurface sensors or signalling mechanisms that play a role in their

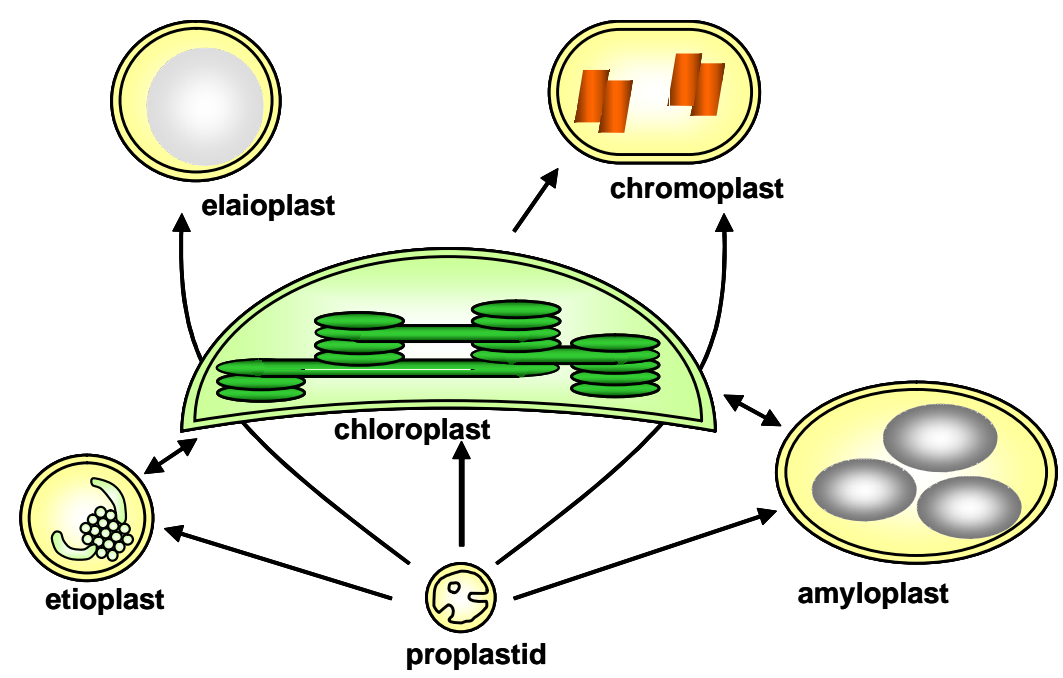

Fig. 1. Diversity of plastid types and their interconversions. Chloroplasts occupy the centre of the figure to signify their evolutionary role as ancestors of all other plastid types, although during ontogeny all plastids derive from embryonic proplastids. development as multicellular organisms, even mechanisms to fight pathogens, that today distinguish plant genomes and were never available to non-photosynthetic eukaryotes.

In this article we will attempt to provide an overview of some of the processes above. The task is arguably overambitious. Fortunately there are a number of excellent reviews that address many of the individual aspects and the reader is referred to them (Sugiura, 1992, 2003; McFadden, 1999; Pyke, 1999; Staehelin and Newcomb, 2000; Flügge, 2001; Mache and Lerbs-Mache, 2001; Soll, 2002; Leister, 2003; Osteryoung and Nunnari, 2003; Wakasugi et al., 2001; Timmis et al., 2004; Dyall et al., 2004; Waters and Pyke, 2004; Jarvis and Robinson, 2004).

\section{Chloroplasts and other types of plastid}

Chloroplasts are the most noticeable feature of green cells in leaves and, excluding the vacuole, probably constitute the largest compartment within mesophyll cells. These cells appear under the microscope as thin layer cytoplasms, appressed between the vacuole and the cell wall and invariably contain one layer of green lens-shaped organelles, between 5 and $10 \mu \mathrm{m}$ in diameter and 3$4 \mu \mathrm{m}$ in thickness (Fig. 2). Depending on species, they number from a few tens to over 100 (Waters and Pyke, 2004). Their obvious primary role is the photosynthesis of carbohydrate. A double membrane, the chloroplast outer and inner envelopes, delimits chloroplasts. Inside, extensive photosynthetic membranes, the thylakoids, extend parallel to the main chloroplast axis, forming flat vesicles, some appearing individually (stromal thylakoids), some organised into stacks or grana, containing an internal space or lumen. The thylakoids appear as discrete units in transverse sections, but actually form in three dimensions an interlinked compartment, enclosing a single lumen (Staehelin and Newcomb, 2000; Mustardy and Garab, 2003). The thylakoid membranes harbour the four main protein or protein-pigment complexes involved in the light reactions of photosynthesis: photosystems (PS) I and II, the cytochrome $b_{6} / f$ complex and the ATP synthase. The arrangement into grana is important, as it allows for the separation between the two PS, with PSII and its main light harvesting complex being limited to granal membranes not in contact with stroma, while photosystem I is exclusively in stroma-exposed thylakoids. This in turn makes it possible to redistribute the harvesting of light according to the prevailing light conditions (Anderson 2000). The ability for this fast redistribution has often been difficult to grasp, in the light of models of the internal three-dimensional structure of membranes inside chloroplasts, with proteins in most granal thylakoids being 'several membrane layers away' from the closest stromal thylakoid. Reassuringly, recent detailed analysis shows that many stromal thylakoids surround and often connect obliquely multiple layers of thylakoids in grana (Mustardy and Garab, 2003).

The stroma, the chloroplast contents outside the thylakoids, is, among others, the site of carbon fixation. Both the thylakoids and the stroma are extraordinarily rich in proteins. The stroma also contains varying amounts of large starch granules 
and small lipid droplets, called plastoglobuli. The lipid component of chloroplast envelopes and thylakoids is different from the rest of the plant, being based primarily on galactolipids instead of phospholipids; as a result a deficiency in galactolipids has severe consequences on chloroplast development (Jarvis et al., 2000). The envelopes are sites of chloroplast membrane lipid biogenesis and also control the exchange of molecules between the stroma and the cytoplasm. The outer envelope is broadly permeable to molecules up to $10 \mathrm{kDa}$, while the inner envelope is much more selective, it contains a sophisticated series of dedicated smallmolecule transporters that allow, among others, the export of photoassimilates (Flügge, 2001).

Chloroplasts are also central to plant metabolism overall. This is important in many respects since there are abundant examples of mutants identified on the basis of plant- or plastid-developmental phenotypes, which have turned out to be defective in one or another aspect of plastid-localised metabolism, probably for direct as well as indirect reasons. Starch synthesis, photoreduction of nitrogen, for all aminoacids and sulphur, for cysteine, biosynthesis of fatty acids, of the phenolic group in aromatic ringcontaining aminoacids and in their derived secondary metabolites (the shikimate pathway), of the purine and pyrimidine base constituent of nucleic acids, of chlorophyll and other tetrapyrroles (although haem is produced in both the plastid and the mitochondria), all take place in chloroplasts (Neuhaus and Emes, 2000). Isoprenoids (also called terpenoids and including carotenoids, steroids and many secondary metabolites), were until recently considered to be produced in chloroplasts from cytoplasmic precursor isoprenoid units, but even these are the product of a major chloroplast anabolic pathway, until recently undetected, the 'non-mevalonate' or methylerythritol pathway (RodríguezConcepción and Boronat, 2002). Carbohydrate oxidation can also take place, through the oxidative pentose phosphate pathway (Neuhaus and Emes, 2000). Several plant hormones, including the isoprenoid-derived abscisic acid, gibberellins and brassinosteroids, are additional products of plastid activity.

In light of this central metabolic role, it is evident that nonphotosynthetic cells would not be able to survive totally deprived of chloroplasts, unless heavily nourished by close neighbours. Such cells contain non-photosynthetic relatives of chloroplasts, generically called plastids (Fig. 1). Meristematic cells contain colourless proplastids, of between 0.2 and $1 \mu \mathrm{m}$ and with very limited internal membrane vesicles, which appear as inner envelope invaginations (Fig. 2B). There are around 10-20 such proplastids per cell (Pyke and Leech, 1992; Waters and Pyke, 2004). The embryo, as well as many cell types not metabolically specialised, also contain proplastids. Plastids with a highly variable morphology, larger than proplastids and with more developed internal membranes, both in many root cells and in very young leaf cells that will eventually contain chloroplasts, have been called ameboid plastids.

One main type of differentiated plastid in many root cells is the amyloplast. This plastid is filled with a store of starch granules generated from imported photosynthate and also has a very active oxidative pentose phosphate pathway, that generates energy to assimilate nitrogen (Neuhaus and Emes, 2000). Amyloplasts are also major constituents of the cells of storage organs, like tubers, cotyledons and seed endosperm (Staehelin and Newcomb, 2000, Waters and Pyke, 2004). Plastids can also specialise in storing lipid and in this case are called leucoplasts, as those accumulating aromatic oils and produced in secretory hairs (trichomes), or elaioplasts, as those in oil-accumulating storage organs, such as oilseeds.

Plastids have also evolved the capacity to accumulate pigments, primarily the isoprenoid carotenoids and xanthophylls and are responsible for the yellows, oranges and reds of many flowers and fruits, the attractants of animals helping transfer pollen or disperse seed. These plastids are then called chromoplasts. Petal cells of flowers with coloured petals convert either proplastids or chloroplasts into pigmented chromoplasts (Weston and Pyke, 1999), while tomato fruit pericarp cells contain during development chloroplasts that, upon ethylene-induced ripening, undergo a transition to chromoplast and accumulate vast quantities of the red carotenoid lycopene (Bramley 2002). Many chromoplast types have been described, which probably reflects the variety of carotenoids, of different solubility and ability to form crystals, which they can accumulate (Waters and Pyke, 2004).

Finally leaf cells, normally containing chloroplasts, need in angiosperms light for the conversion of protochlorophyllide into chlorophyll. When light is unavailable or insufficient, as is often the case in cotyledons of germinating seedlings or exceptionally in young leaf cells, proplastids accumulate large amounts of thylakoid lipids with the complex of protochlorophyllide and a form of the enzyme responsible for its light-driven reduction, protochlorophyllide reductase A (Armstrong et al., 1995; Vinti et al., 2005). Such plastids are called etioplasts, as dark-grown seedlings are said to be etiolated (Fig. 2A). Their internal membranes can be seen as a semicrystalline structure called the prolamellar body. Upon illumination, flat membrane sacs will emerge from the prolamellar body that will eventually become thylakoids with their normal photosynthetic complexes.

\section{Plastid genetics}

Shortly after the rediscovery of Mendel's laws, at the start of the 20th century, it was reported that some variegated mutations were transmitted in a way that did not obey such laws, rather the mutation was only maternally inherited (see Sugiura, 1992). This was, interestingly, at approximately the same time that a Russian cell biologist, Mereschkowsky, first proposed that plastids behaved like and could be, reduced, en-slaved forms of blue green algae, now cyanobacteria, inside plant cells (see Martin and Kowallik, 1999). However, it would be years before the two observations would actually come to reinforce each other through backing up a model of 'endosymbiosis' (Dyall et al., 2004).

\section{Chloroplast genome}

It was demonstrated in the 1960s and early 1970s that chloroplasts contain their own DNA molecule (Fig. 3A). Analysis of this plastid genome results in a circular map, the circle having, in higher plants, a size ranging between 120 and $160 \mathrm{Kbp}$ (135 and $154 \mathrm{Kbp}$ respectively in rice and Arabidopsis). The only higher plant exception to that size range is Epiphagus (size 70 $\mathrm{Kbp}$ ) and other parasitic, non-photosynthetic plants (Bungard, 2004). Plastids are highly polyploid; proplastids contain around 20 copies of the genome (approx. 400 per meristematic cell), while chloroplasts contain around 100 copies (10,000 copies per cell) (Sugiura, 1992). These genomes are not necessarily organised 
in individual circular molecules, one genome per circle, instead it appears that long, polyploid linear molecules and branched molecules undergoing replication are abundant (Bendich, 2004). To date the sequence of the full chloroplast genome of a total of 45 photosynthetic organisms has been determined, of which 22 are seed plants. A comprehensive list of fully-sequenced chloroplast genomes is currently available athttp://megasun.bch.umontreal.ca/ ogmp/projects/other/cp_list.html. DNA exists in plastids in discrete regions, in the form of nucleoids associated to the inner envelope. Nucleoids contain DNA-binding proteins, one of which is plastid envelope DNA-binding and another turns out to be a bifunctional protein with a second role as the enzyme sulphite reductase (Sato etal., 2003). A DNA polymerase, the origins of replication (different between monocots and dicots) and a number of topoisomerases have been identified (Mache and Lerbs-Mache, 2001).

Higher plant chloroplast DNA is very highly conserved. In fact phylogenetic analyses using chloroplast genome sequences have concluded that a single endosymbiotic event between a mitochondrion-containing eukaryote and an unknown cyanobacteria, took place and gave rise to all existing chloroplasts (Martin et al., 2002; De las Rivas et al., 2002; Timmis et al., 2004). The early event was soon followed by diversification into what are now the chloroplasts of red alga (and, remarkably, those of organisms which have secondarily engulfed red algae, like diatoms) and those of green algae and eventually land and seed plants (Martin et al., 2002; De las Rivas et al., 2002). The genome has a physical peculiarity, the presence of two copies of the same large region, separate and in inverted position (large inverted repeat). The regions outside the repeats are called large single-copy and small single-copy regions. The size of the repeat is variable, this accounting for most of the variation in genome sizes. Chloroplast genomes contain between 120 and 135 genes, 130 in the model species mentioned above, of

TABLE 1

\section{GENE CONTENT OF THE ARABIDOPSIS CHLOROPLAST GENOME}

\begin{tabular}{|c|c|c|}
\hline Function & Genes & Number of genes \\
\hline \multicolumn{3}{|l|}{ RNA-encoding } \\
\hline ribosomal RNA & $r r n 4.3-r r n 23$ & 8 \\
\hline tRNA & $\operatorname{trn} A-\operatorname{trn} V$ & 37 \\
\hline \multicolumn{3}{|l|}{ Transcription/translation } \\
\hline RNA polymerase subunits & $r p o A, B, C 1, C 2$ & 4 \\
\hline Intron splicing (putative) & matk & 1 \\
\hline Ribosomal proteins & rps2-rps 19; rp/2-rp/36 & 26 \\
\hline \multicolumn{3}{|l|}{ Photosynthesis } \\
\hline Photosystem II (or its assembly) & $p s b A-p s b l ; y c f 9$ & 15 \\
\hline Photosystem I (or its assembly) & psaA-psaJ; ycf3; ycf4 & 7 \\
\hline Cytochrome $b_{6} / f$ (or assembly) & petA-petG; ORF31 & 5 \\
\hline ATP synthase & atpA-atpl & 7 \\
\hline Rubisco (large subunit) & $r b c L$ & 1 \\
\hline \multicolumn{3}{|l|}{ Others } \\
\hline NADH complex & NdhA-ndhJ; psbG & 12 \\
\hline Proteolysis & $c / p P$ & 1 \\
\hline Lipid biosynthesis & $a c c D$ & 1 \\
\hline \multirow[t]{2}{*}{ Various } & $y c f 1$ (FtsH?), yct2 (ABC?), & 5 \\
\hline & ycf5, ycf6, ORF77 & \\
\hline
\end{tabular}

Note: Many other higher plant chloroplast genomes also encode the translation initiation factor gene infA. which 76 are protein-coding genes, the rest encoding other RNAs (Table 1). The chloroplast genome is concerned mostly with encoding components of the four thylakoid photosynthetic complexes, or proteins necessary for their assembly and also encodes part of the genetic machinery necessary to do so, this genetic machinery being of a eubacterial type (Fig. 3A). Through the use of bioinformatics techniques, including comparisons of large scale gene clusters to full cyanobacterial genomes, two large open reading frames of so far unknown function, $y c f 1$ and $y c f 2$, have been recently proposed to encode one of the $\mathrm{FtsH}$ group of proteases and an ATP-binding cassette transporter respectively (De las Rivas et al., 2002).

\section{Organisation of chloroplast genes}

As in bacteria, many genes are organised in operons and expressed as polycistronic units. In one instance this is more the case than in bacteria themselves: the rpl23 operon of chloroplasts contains genes that in $E$. coli are encoded in three separate, although contiguous, operons (Sugiura, 1992). Fifty transcriptional units exist overall, giving rise to the need for post-transcriptional processing. Most operons encode subunits of the same molecular complex, although hybrid ones also exist ( $p s b B$ and pet genes are expressed as a single operon). In some cases it includes intron splicing: contrary to the general case in bacteria, some chloroplast genes contain introns, but these relate to mitochondrial or unusual yeast introns, with a conserved folding pattern, rather than conserved splice sites (Sugiura, 1992).

\section{Plastid genome expression}

The chloroplast genome encodes four core subunits, rpoA, rpoB, rpoC1 and rpoC2, of an E. coli-like RNA polymerase, called plastid-encoded polymerase or PEP (Fig. 3A). Accordingly with this eubacterial-type transcription machinery, many plastid genes have conserved -35 (TTGACA) and -10 (TATAAT) promoter sequences (Sugiura, 1992). The core polymerase of $E$. coli does not recognise promoters, needing for this to form a complex with one sigma-70 subunit, which determines promoter specificity. Plant nuclear genomes encode these sigma factors (Isono et al., 1997), a small family of 6 AtS/G genes being present in Arabidopsis. These sigma factors can be assembled with $E$. coli core subunits and form an RNA polymerase active in vitro (Suzuki et al., 2004). At the same time, mutants of the plastid ribosome-deficient albostrians mutant of barley (Hubschmann and Börner, 1998) and tobacco plants with the rpoB subunit knocked-out (Allison et al., 1996) are viable and show detectable plastid transcription. The search for a separate, nuclear-encoded plastid polymerase (NEP) led to the identification of a single-subunit RNA polymerase, with homology to polymerases from bacteriophage or from yeast mitochondria (Hedtke et al., 1998). Three genes for organellar NEP exist in Arabidopsis, one being targeted to mitochondria, one to the plastids and one to both (see Cahoon and Stern, 2001). Plastid NEP-recognised promoters often have a conserved YRT motif immediately upstream of the transcription start, although this is not always the case (Weihe and Borner, 1999). NEP and PEP functions follow, to some extent, an elegant sequential role: plastid genetic machinery genes, including PEP genes, are first transcribed by NEP, while this PEP then is chiefly responsible for transcribing photosynthesis-related genes. However NEP continues to be expressed even in green leaves and many photosynthe- 
Fig. 2. Developmental or environmental influences on chloroplasts. (A) Cotyledons of seedlings grown in the dark (left) exhibit etioplasts, while those in the light (right) contain chloroplasts. (B) Meristematic cells contain proplastids, which quickly differentiate into chloroplasts with increasingly complex thylakoid structures as cells themselves differentiate with leaf development. The conversion is slowed down in the 'virescent' cue6 Arabidopsis mutant, in which the delay reveals the gradient of maturation of leaf mesophyll cells. (C) Chloroplasts of high (top) or low-light (bottom) exposed Arabidopsis leaf cells (shown in cross section) exhibit a different composition, particularly in the abundance of light-harvesting antenna complexes and as antenna complexes are grana-localised, low-light chloroplasts contain more abundant grana. (D) Mesophyll cells from a 'high-light' Arabidopsis leaf (left) develop as a thick palisade layer of highly elongated cells, the elongation being matched by an increase in chloroplast numbers, so that the cells appear as 'tunnels' coated internally in one layer of chloroplasts. Chloroplasts are visualised in this confocal Z-axis view of stacked sections as globules of red (chlorophyll) fluorescence. (E) Plastids from the inner mesocarp of mature green tomato fruit, initiating the transition from chloroplast to chromoplast, under confocal imaging. The plastids contain both chlorophyll and green fluorescent protein (GFP), which appear yellow when both are present whereas with only GFP appear green. Thin, green, tubular stromules, rare in mesophyll chloroplasts, are evident in most of the plastids. Scale bars (for plastids): $1 \mu \mathrm{m}(\mathrm{A}-\mathrm{C})$ and 10 $\mu m(D, E)$.

sis-related genes can be transcribed by both polymerases (Cahoon and Stern, 2001).

Whether transcription is the most important level of regulation of gene expression has been a matter of much debate. Overall that notion is supported by the fact that protein levels, translation activity and mRNA levels correlate (Mullet, 1993). However it is also the case that much evidence for translational regulation exists (Bruick and Mayfield, 1999). In general plastid-encoded mRNAs have a long halflife, of between hours and days and recently a large family of nuclear genes, for pentatricopeptide-repeat proteins, appear in many cases to encode organellar-targeted RNA-binding proteins (Lurin et al., 2004).

\section{The plastid proteome}

Since the plastid genome encodes less than 80 proteins, it is obvious that a much greater number is required for the variety of plastid functions. Many genes, particularly for photosynthetic proteins, have been individually identified as being encoded in the cell's nuclear genome. The availability of full genome sequences of plants has revealed the extent and range of plastid-contained proteins. Nuclearencoded proteins, as discussed below, are translated in the cytoplasm and imported into the plastids, the targeting signal being localised at the $\mathrm{N}$-terminus of the proteins as a transit peptide or signal sequence (Soll, 2002). Algorithms have been developed based on known properties of these signals and further refined
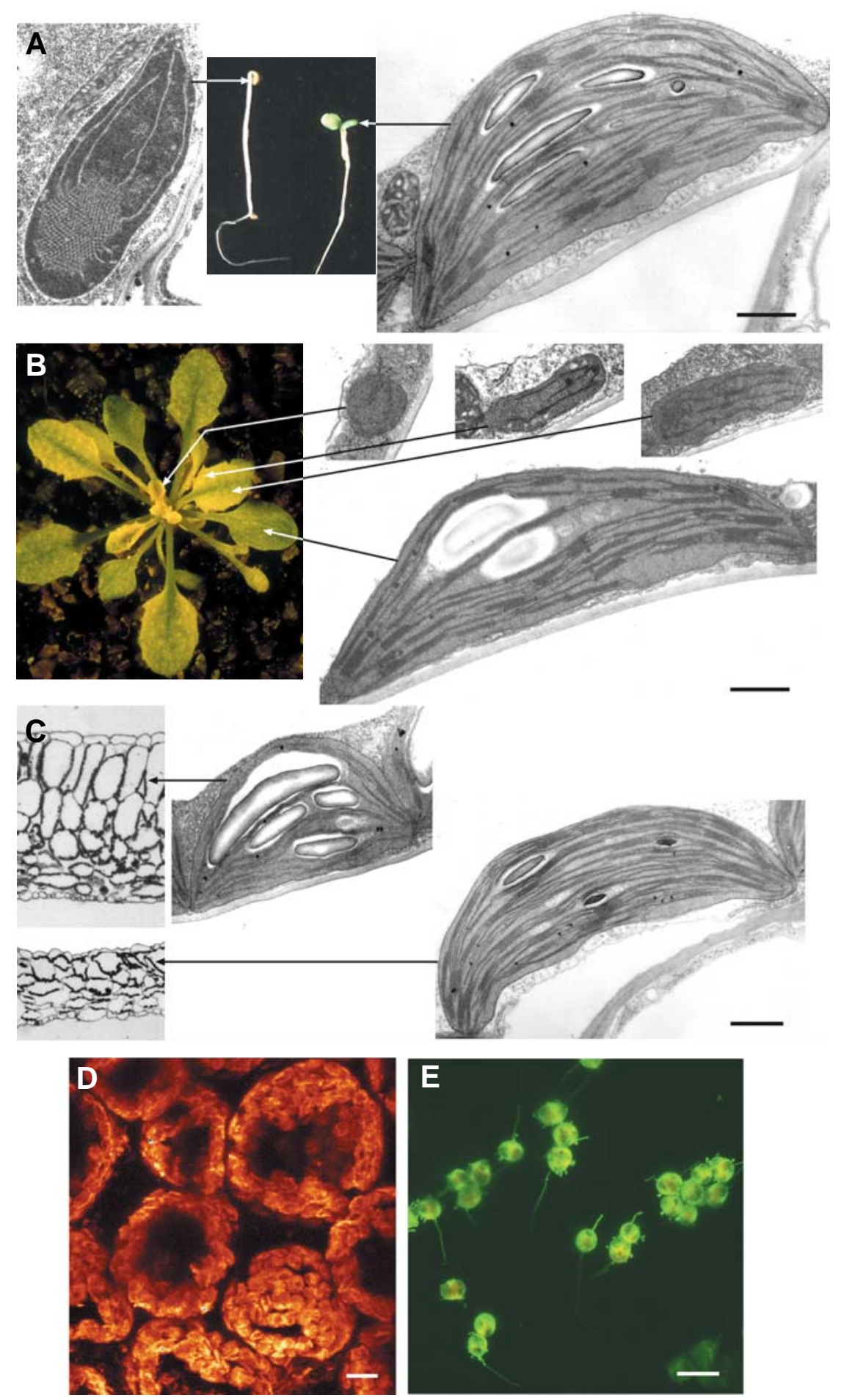

('trained') on experimentally determined sequences to identify transit peptides, the most faithful to date being TargetP (http:// www.cbs.dtu.dk/services/TargetP/). Use of this algorithm on the full Arabidopsis genome sequence and corrections for its experimentally-determined specificity and sensitivity, leads to a prediction of a total of 3,100 proteins as chloroplast targeted (Abdallah and Leister, 2000; Leister, 2003). A combination of algorithms, on the other hand, has estimated the number in Arabidopsis at around 
2,100 , while that in rice is 4,500 (Richly and Leister, 2004). Only about half of the predicted Arabidopsis chloroplast proteins are shared by rice and play a role in metabolism, energy-generation and transcription. The low number is surprising and suggests there may be large diversity in the fine detail of plastid functions across groups, although it may also be a consequence of ambiguities derived from the use of bioinformatics tools, both in the prediction and in the detection of homology. Work is intensively being carried out in several laboratories to catalogue every plastid protein directly detected using mass spectrometry-based proteomic techniques. This has been done for thylakoids or chloroplast envelopes (Peltier et al., 2002; Ferro et al., 2003), as well as for complete chloroplast and envelope-enriched preparations (Klefmann et al., 2004). The latter authors identified a total of 690 proteins from Arabidopsis. Two databases of plastid proteins have been produced: PLprot currently contains the data of Klefmann and co-

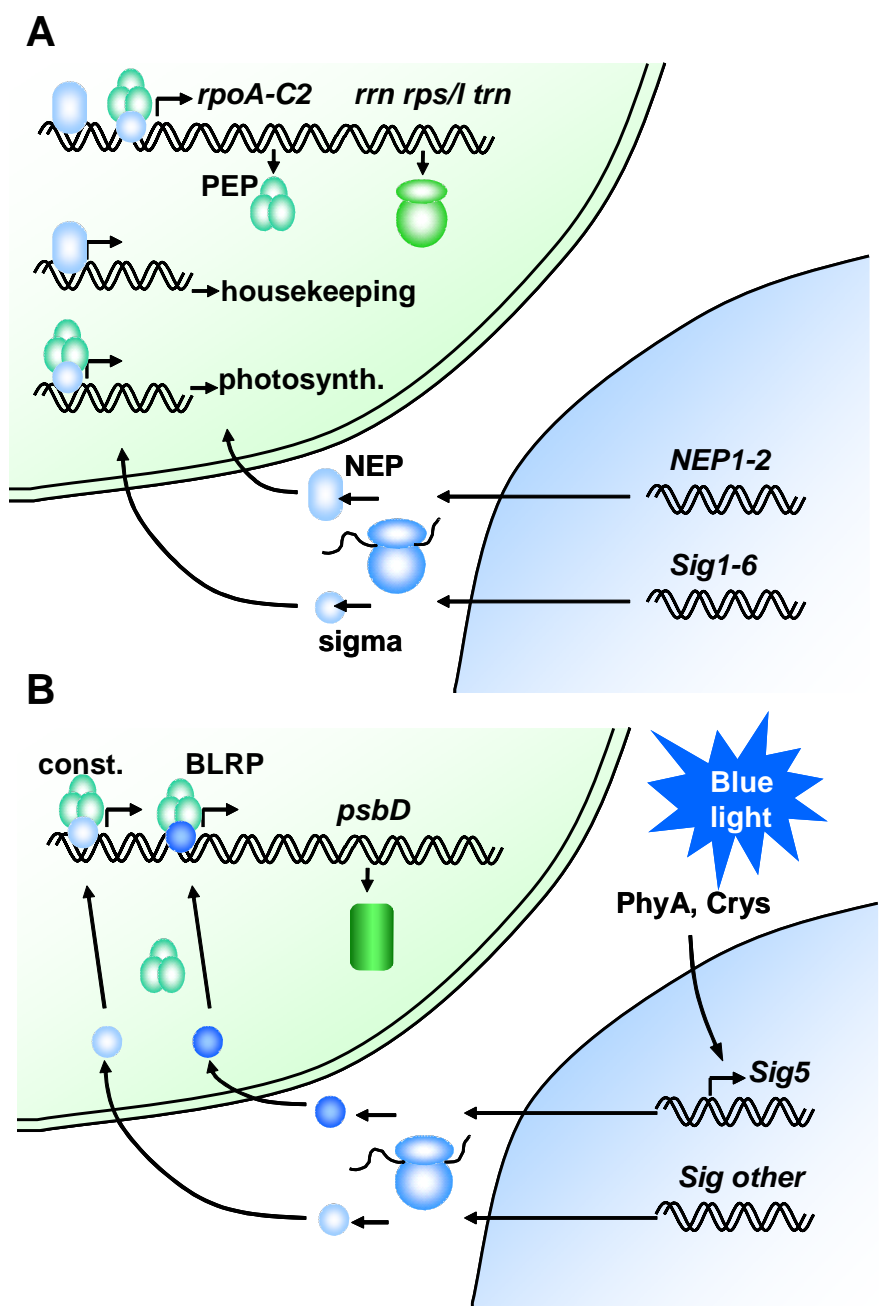

Fig. 3. Plastid genome expression. (A) Plastid genetic machinery and contributions of the nucleargenome towards it. The chloroplast (upper) and nucleo-cytoplasmic (lower) ribosomes are also indicated. PEP: plastidencoded RNA polymerase. NEP: nuclear-encoded RNA polymerase. Photosynth.: photosynthesis. (B) Example of regulation of a chloroplastencoded gene psbD, by an environmental cue, blue light, perceived by extraplastidic sensors, phytochrome A (PhyA) and cryptochromes (Crys). $B L R P$, blue light-responsive promoter; Const, constitutive promoter. workers from Arabidopsis chloroplasts, but will be supplemented with data from other plastid types (http://www.pb.ipw.biol.ethz.ch/ $\sim$ w3pb/index.php?toc=91), while Plastid Proteome Database, PPDB, contains both experimentally determined (Peltier et al., 2004) as well as predicted chloroplast proteins in Arabidopsis and maize (http://ppdb.tc.cornell.edu). The study by Klefmann et al. (2004) identified proteins in many functional categories, including 'energy' (primarily photosynthesis) and metabolism, among others, of amino acids and carbohydrate, but also detected a large number of transporters, particularly envelope-associated, proteins involved in cell defence, gene expression, protein fate (folding and modification), even DNA replication and cell cycle. Interestingly, as a general rule, simultaneous monitoring of global gene expression detected a broad correlation between amount of transcripts and amount of protein, measured as frequency of detection. This suggests a primary role for transcription/transcript accumulation in the regulation of gene expression for chloroplast-targeted proteins. The correlation, however, was pathway-specific. One surprising finding of this study was the fact that over one third of proteins identified did not have a signal peptide predicted by TargetP. It is known that a number of outer envelope plastid proteins posses a secretory pathway-related targeting signal, which nevertheless leads to envelope localisation unless altered (Lee etal., 2001). This suggests that our estimates of chloroplast-targeted proteins may under-represent their true number and that novel pathways and functions may still emerge. Both proteomics and genetics, through the large-scale identification of mutations in essential plastid genes, using Arabidopsis (Leister, 2003) or maize (Stern et al., 2004; see the Photosynthetic Mutant Library at http:// chloroplast.uoregon.edu/) will play a role.

\section{Gene transfer to the nucleus and contribution of the endosym- biont to the host}

The global comparisons of a full plant genome with that of cyanobacteria, other representative prokaryotes and yeast (Martin et al., 2002) has provided an estimate of around 4,500 Arabidopsis genes derived from the chloroplast endosymbiont ancestor and has pointed to the cyanobacteria Nostoc as its closest relative among those with fully determined genomes. This highlights the massive scale of gene reduction in the organelle and transfer to the nucleus (Timmis et al., 2004). The complete transfer probably involves the incorporation into the nucleus of copies of the plastid gene, the acquisition of plastid transit peptides, either by integration next to existing ones or by generation of new ones from previous upstream sequences and finally the loss of the organellar copy. The integration of plastid genes into the nuclear genome has been monitored through selection of transfer events with a marker which was only active when expressed in the nucleus and has turned out to be unexpectedly easy (in one out of 16,000 gametes tested; Huang et al., 2003). In fact many instances of recent transfers have been detected, including an almost complete integration of the chloroplast genome into rice chromosome 10 (The Rice Chromosome 10 Sequencing Consortium, 2003).

One naive view would be that cyanobacterial genes were largely transferred to the nucleus and retargeted back to the organelle. This appears to be a frequent case, but far from the general rule. The genomes and their functions have been extensively reshuffled (Timmis et al., 2004). Proteins from host genes with equivalent functions may have been targeted to the plastid and replaced the 
resident proteins; for example two of the Calvin cycle enzymes, triosephosphate isomerase and fructose bisphosphatase, are of mitochondrial origin (Martin and Herrmann, 1998). Conversely, originally cyanobacterial genes have explored novel functions. Genome-wide estimates of the destinations of ancestral cyanobacterial genes have revealed that less than half the total has been retargeted to the chloroplast, the second most common destination being the secretory pathway (endoplasmic reticulum, Golgi, plasma membrane and cell wall export), but others being predicted as cytoplasmic and mitochondrial (Martin et al., 2002). Even if, as seen above, some of the proteins predicted as targeted to the secretory pathway end up being chloroplast envelope proteins, there is still a wealth of genes contributed by the endosymbiont to the host's genome. The most common functional categories among those are biosynthesis and metabolism, signal transduction, 'cellular responses' and energy generation (Martin et al., 2002). This has left its mark in the exceptionally large primary and secondary metabolic abilities of plants, as well as in their developmental toolkit. Among many examples, hormonal sensory mechanisms, including the ethylene and cytokinins receptors, use two-component histidine kinases and the same can be said of environmental phytochrome photosensors (see http:// www.bio.unc.edu/research/two-component/default.htm; Fankhauser, 2001). Such kinases are widespread in eubacteria, including cyanobacteria, but exceptionally rare in non-photosynthetic eukaryotes (none in metazoans, Stock et al., 2000). It is not just because of their photosynthetic capacity that plastids make plants unique.

\section{Why a plastid genome?}

Given the massive reduction in the number of genes, which in cyanobacterial genomes range from 3000 to over 7000 and in chloroplasts are around 100 (Timmis et al. 2004), the question as to why has a genome been retained at all in the organelle appears legitimate. An overview of the proteins whose genes have been transferred and those that have not shows a general pattern: the majority of retained proteins encode thylakoid membrane components (or genetic machinery proteins necessary to produce those). One explanation would be that it has been primarily highly hydrophobic membrane proteins, particularly difficult to import and assemble correctly, that have been retained by the organellar genome. This would be consistent with the pattern of retention of mitochondria-encoded proteins (Dyall et al., 2004). An intriguing alternative has been proposed. As we will discuss, chloroplasts are capable of using their redox processes as signals to regulate the expression of plastid-encoded genes, rapidly, in response to sudden changes in environmental circumstances, like changes of light quantity. Rapid regulation following a burst of light in a sunfleck may make the difference between survival and catastrophic oxidation for a chloroplast and the cell that harbours it. The need for such a rapid redox regulation may explain the retention of genes by both chloroplasts and mitochondria (Allen, 2003).

\section{The biogenesis of plastids}

\section{Plastid protein import machinery}

Nuclear-encoded proteins are translated in cytoplasmic ribosomes and, unless they are targeted to the outer envelope, need to be brought into the chloroplast crossing two plastid envelopes
(Fig. 4). Proteins destined to be imported carry an $\mathrm{N}$-terminal transit peptide, generally between 20 and 80 aminoacids. Transit peptides of different proteins show no obvious sequence conservation, their general physical characteristics consisting of an abundance of hydroxylated, positively charged and small aminoacids and a low abundance or absence of acidic or large hydrophobic ones. A common feature of transit peptides appears to be a site for phosphorylation at a Ser or Thr residue, this site being bound by 14-3-3 proteins and a chaperone into what has been termed a guidance complex (May and Soll, 2000). The functional significance of this complex, however, is in question, as the phosphorylation site can be mutated without obvious detrimental effects (see Jarvis and Robinson, 2004).

The import is carried out by protein complexes located in both membranes: translocon of the outer envelope of chloroplast (Toc) and translocon of the inner envelope of chloroplast (Tic) (Soll, 2002). Our understanding of the function of Toc is greater than that of its inner envelope counterpart. The Toc complex, as first purified biochemically from pea chloroplasts, is composed of three subunits, Toc159, Toc75 and Toc34 (Keegstra and Froehlich, 1999), as well as probably Toc64 (see Soll, 2002). Toc75 forms a channel across the outer membrane. It has a predicted structure similar to bacterial porins, with $16 \beta$-strands, into what has been called a $\beta$-barrel. The channel is selective to cations, as expected from the nature of transit peptides (Soll, 2002). Toc159 and Toc34 jointly function as receptors and docking sites for the polypeptides to be imported. They both are guanosine triphosphatases (GTPases) with a region of high homology. When Toc34 binds GTP, it shows much higher affinity for substrates and the binding causes the hydrolysis of GTP, followed by the release of guanosine diphosphate (GDP) and the substrate. It is possible that the same phenomenon occurs in the associated component, Toc159 and that the conformation change associated with the hydrolysis of GTP gates the import channel (Sun et al., 2002). A preliminary structure of purified Toc complexes shows a ring (presumed formed by Toc75 subunits) leaving four pores crossing the membrane, with a middle structure and fingers protruding perpendicular to the membrane, consistent with the soluble receptor domains of Toc159 and Toc34 (Schleiff et al., 2003)

Each subunit of the Toc and Tic complexes is encoded by a small family of genes (Jackson-Constan and Keegstra, 2001). Recent genetic evidence has shown that defects in individual genes are not incompatible with survival, indicating a degree of redundancy among those genes. For example the co-receptor Toc34 is encoded in Arabidopsis by two genes, atTOC33 and atTOC34. The plastid protein import 1 (ppi1) mutant contains a disruption of atTOC33 that leads to defective chloroplasts (Jarvis et al., 1998). The mutant ppi3, a knockout of atTOC34, has only a minor phenotype; the loss of both forms, however, is lethal (Constan et al., 2004). A loss in ppi2 of atToc159, the main form of the receptor, leads to chloroplasts with severe loss of thylakoids and plants unable to grow autotrophically (Bauer et al., 2000). Loss of either of the two other family members encoding alternative forms of Toc159, namely at Toc132 and atToc120, leads to no obvious phenotype, but loss of both is severely deleterious (Kubis et al., 2004) or lethal (Ivanova et al., 2004), presumably depending on the growth conditions, while loss of atToc159 and atToc132 is lethal in every case (Kubis et al., 2004).

Tic complexes contain at least six subunits. The largest one, 
Tic110, often co-purifies with Toc complexes, making it likely that they both act in tandem, at points in which both plastid envelopes contact each other. Like Toc75, Tic110 can form a channel for cations. Since Tic110 also folds into a number of predicted $\beta$ strands, it is possible that it also forms a $\beta$-barrel (Heins et al., 2002). This all leads to assume Tic 110 forms the protein import pore across the internal membrane. However there is conflicting evidence and claims in the literature, with a small Tic component, Tic20, having also been proposed to play this role (see Jarvis and Robinson, 2004). A number of chaperones associate with the Tic complex and may provide the pulling power that drives the transport of the polypeptide through the two pores (Soll, 2002). Once across the envelope, a stromal processing peptidase cleaves the transit peptide, leaving the mature protein to fold in the stroma or continue its journey.

Proteins destined for the thylakoid membranes or the thylakoid lumen use a second signal sequence for the final leg of their journey. Such proteins, therefore, need a bipartite transit peptide, with two domains, one for 'envelope-transit' and one for 'thylakoid-targeting' (Robinson et al., 2001). The thylakoid-targeting signal is comparable to signals used by prokaryotes to export or secrete proteins. Plastids use a system comparable to bacteria, in which the translocation takes place through a SecA protein, but have also evolved an alternative route, in which the $\mathrm{pH}$ gradient across the thylakoid is used to drive the translocation (the $\Delta \mathrm{pH}$ dependent pathway, also called Tat as it uses a Translocase for domains with a $T$ win- $A$ rginine motif). Integral thylakoid membrane proteins are either targeted through a third type of domain, recognised by a bacterial-type signal recognition particle (SRP), or apparently integrate spontaneously, using the polypeptide's biophysical/solubility properties (Robinson et al., 2001). Proteins that do use a thylakoid-targeting domain have it finally cleaved off in the lumen by a thylakoid processing peptidase.

\section{Plastid division machinery}

Plastids only originate from pre-existing plastids. The process during which one leaf primordium cell, containing 20 proplastids, gives rise to several hundred mature leaf cells, each carrying around 100 chloroplasts, must be accompanied by massive plastid division (Fig. 5A). Under the microscope, this appears similar to bacterial fission; a plastid undergoes a constriction, with a ring of electron-dense material appearing at both the cytoplasmic and stromal sides of the envelopes at the middle of the plastid. Eventually the physical constriction fully separates the two daughter plastids (Pyke, 1999; Marrison et al., 1999; Osteryoung and Nunnari, 2003).

Our understanding of the mechanisms of plastid division has progressed in two parallel fronts. The genetic approach has been based on the identification of mutant 'accumulation and replication of chloroplasts' (arc) plants with altered numbers of plastids (Pyke and Leech, 1994; Pyke et al., 1994). This has been aided by the fact that altered plastid division turns out to not impair the build-up of the total chloroplast compartment of the cell, i.e., in mutants with altered division, at least in leaf cells there is an inverse relationship between the number of chloroplasts in the cell and their size (Marrison et al., 1999). In the extreme arc6 mutant, only one large chloroplast occurs per mesophyll cell. The phenotype of two arc mutants, arc3 and arc5, is consistent with a defect in the accumulation of chloroplasts in mesophyll cells, without compromising proplastid division in meristematic tissue, therefore leading to the presence of only around 20 chloroplasts per cell (Pyke, 1999). This suggests that there are separate mechanisms, or at least separate gene family members, playing roles in division of plastids at different stages. The genetic approach has also yielded the ARTEMIS protein (Fulgosi et al., 2002). When ARTEMIS is mutated, plastid division is not completed but separate thylakoid systems can be identified. This demonstrates that thylakoid systems, constituting a single, integrated structure per chloroplast, are divided by a process which is to some extent distinct from the division of the chloroplast.

A complementary, genomic approach to understanding plastid division was sparked by the identification in Arabidopsis of a homologue of the bacterial cell division gene Fts $Z$, whose product was targeted to chloroplasts (Osteryoung and Vierling, 1995). Defects in Fts $Z$ in $E$. coli lead to defects in division without impairing growth at non-permissive temperature, resulting in a filamentous phenotype. The protein is a GTPase, that is, it binds and hydrolyses GTP. It also has a domain with homology to eukaryotic tubulin, can polymerise into filaments and is generally accepted as tubulin's prokaryotic ancestor. The FtsZ proteins of chloroplasts (FtsZ1 and FtsZ2) polymerise into a ring at the inner envelope and GTP hydrolysis may help generate the constriction force (Osteryoung and Nunnari, 2003) (See Fig. 5B). The plastid division rings themselves, however, are associated to but distinct from FtsZ (Miyagishima et al., 2001). In bacteria, the FtsZ division ring is placed in the middle of the long bacterial rod through the action of Min proteins, mutations in which lead to asymmetric divisions and consequently the appearance of mini-cells. Chloroplast MinD (Colletti et al., 2000) and MinE (Itoh et al., 2001; Maple et al., 2002) have also been identified. As in some bacteria, MinE could act by excluding FtsZ from the chloroplast poles. MinD would contribute to this process and turns out to be the defective gene in the arc11 mutant (Fujiwara etal., 2004). Its molecular role explains the variable size of chloroplasts in arc11.

The ARC5 gene encodes a dynamin-related protein (Gao et al., 2003). Dynamins are involved in eukaryotes in membrane severing, for example during endocytosis or membrane trafficking and, interestingly, also in mitochondrial division. The other functions of dynamins suggest that ARC5 could play a role in completing off the separation of membranes, once the first stages of division have created a small enough constriction and this is consistent with the incomplete-division, dumbbell shape of arc5 chloroplasts. $A R C 6$, on the other hand, encodes a DnaJ related protein, a chaperone partner and is considered to assist in the assembly of the FtsZ ring (Vitha et al., 2003).

\section{Plastid 'plasticity' and stromules}

The examination of live chloroplasts, carried out around 100 years ago, gave rise to the first proposal for their endosymbiotic origin (Martin and Kowallik, 1999). Perhaps one striking observation, later forgotten, was that showing plastids emitting protrusions of a very dynamic nature, mobile, produced and retracted within a few minutes. Some of the first examinations of chloroplasts from plants engineered to express a green fluorescent protein (GFP) marker targeted to chloroplasts, led to the rediscovery of such protrusions (Köhler et al., 1997). Since they are able to carry GFP contained in the stroma, the tubules were named 'stromules'. Subsequent work has confirmed that stromules can 
actively transport endogenous protein and that the extent of stromule production is highly dependent on the cell type and type of plastid (Köhler and Hanson, 2000). The nature of stromules in chloroplasts in green tomato fruit, during their transition into chromoplasts in ripe fruit, has been examined in detail (Waters et al., 2004). The basic findings were that stromules increase in frequency as plastids become further apart during cell expansion, that chloroplasts display the lowest number of stromules and that a ripening inhibition mutation causes a reduction in stromule formation, as conversion into chromoplasts is arrested. This suggests that stromules are associated primarily with non-photosynthetic plastids. One possible function of stromules is to provide an increase in the plastid surface area. A role helping to integrate the total ensemble of plastids into a coordinated single plastid compartment is less likely but cannot be dismissed yet, as occasional pairs of plastids can be seen joined together by stromules (Pyke and Howells, 2002) and exchange of marker proteins is possible (Köhler et al. 1997)

\section{The origin and role of organelle-specific functions}

Our current understanding of chloroplast development allows us to address the question of how did the original endosymbiont adapt to become a fully integrated organelle in its host. The organelle, like its ancestor, was still required to divide and had a readily available set of prokaryotic cell division proteins allowing it to do so. Indeed chloroplasts utilise MinD and MinE to position the FtsZ ring, which forms with the assistance of ARC6, a homologue of cyanobacterial Ftn2. All of these proteins retained the basic function they possessed in the free-living cyanobacterium. The organelle, on the other hand, enrolled a dynamin-related protein to complete the constriction of the plastid envelopes, as dynamins were already doing in eukaryotic membrane trafficking and, indeed, in mitochondrial division. The consideration that this final function was recruited from pre-existing eukaryotic machinery for the maintenance of mitochondria is attractive. In one known case, ARC3, the origin of the protein itself is dual: it is a chimeric protein with homology to FtsZ plus an additional domain consisting of a portion of a eukaryotic signal transduction protein, phosphatidylinositol phosphate kinase (Shimada et al., 2004).

Meanwhile, plastid protein import was a novel requirement emerged from the symbiotic way of life and the vast degree of migration of genetic control to the cell's nucleus that it brought. Where did the elements come from? As we have seen, plastids resorted to modifying the function of porins, proteins involved in secretion, basically inverting the direction of their transport. Interestingly, some of the minor components of the Tic complex are also related to aminoacid permeases (Dyall et al., 2004). Pulling power for translocation was also required and cyanobacterial chaperones/heat shock proteins provided this. However the outer pore required gating and for this GTPases of eukaryotic origin and with homology to the $R A S$ oncogene were recruited (Toc159, Toc34). The emerging picture is that the organelle utilised pre-existing cyanobacterial elements for both processes, more so for division, but that in both cases it also resorted to available eukaryotic proteins, as it did to distinguish proteins in need of being translocated.

Another question worth asking is whether the organelle required active division at all. arc6 mutant plants and plants overexpressing almost any component of the plastid division machinery display one or two giant chloroplasts per mesophyll cell, but macroscopically are remarkably normal under laboratory conditions (Pyke et al., 1994; Fujiwara et al., 2004). Hornworts, bryophytes that form a sister group of vascular plants (Willis and McElwain, 2002), naturally have a single, large chloroplast per cell, in common with many green algae. A key answer may be environmental adaptability. Chloroplasts adjust, among other ways, physically to prevailing light conditions, displaying an accumulation response towards low-intensity light and an avoidance of strong, potentially damaging light, both movements being activated by phototropins (Sakai et al., 2001). It has been demonstrated that tobacco plants with altered levels of FtsZ, showing between one and three large chloroplasts per mesophyll cell, perform worse under both low light (reduced photosynthetic performance) and high light environments (greater incidence of photodamage) than wild type plants (Jeong et al., 2002).

\section{Plastids are under the control of developmental signals}

\section{From proplastids to chloroplasts}

The integration of plastids into the biology of the plant cell and the diversity of plastid functions, make it necessary for the organelle to show 'plasticity' and respond to the signals that control the host cell type. Plastids in their primary type, chloroplasts, for example, are not inherited as such from the previous generation. Photosynthetic leaf cells containing chloroplasts derive from meristematic cells containing proplastids. Cereal or grass leaves, with their parallel veins, are formed from broad primordia in meristems and a very clear gradient of differentiation

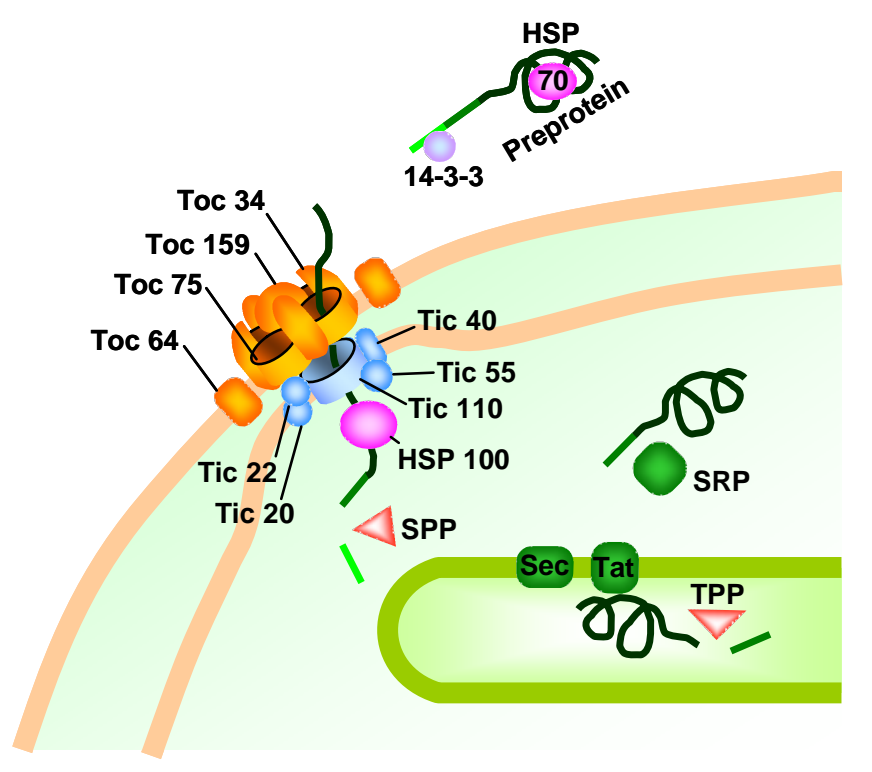

Fig. 4. Plastid protein import machinery and its key components. The model for the Toc complex is consistent with the observations from Schleiff et al. (2003). Both the involvement of 14-3-3 proteins as import guides and the model for Tic are hypothetical; for example conflicting data exist as to whether Tic110 or Tic20 play the role of import pore. Import into the thylakoids occurs through involvement of one of the routes shown, depending on the protein. Some membrane proteins integrate without involvement of any of the mechanisms shown ('spontaneous route'). SPP: stromal processing peptidase. TPP, thylakoid processing peptidase. 
results, with older cells at the tip of the leaf containing a full complement of mature chloroplasts, while at the leaf base cells have undergone division more recently, possess thinner walls and contain a smaller number of developing chloroplasts. The gradient in plastid development manifests itself as very active plastid DNA replication in the meristematic region, followed by high transcriptional activity and eventually the massive build-up of photosynthetic complexes (Baumgartner etal., 1989). Leaves of developing dicotyledons such as pea have been examined in a temporal sequence and show consecutive, partly overlapping stages of plastid DNA replication, transcription of the genetic machinery and transcription for photosynthesis proteins (DuBell and Mullet, 1995a, 1995b). Leaves of dicotyledons like Arabidopsis also show a spatial gradient in cellular differentiation, with cells at the distal end and in the vicinity of the mid vein being first to reach full differentiation (Pyke et al., 1991). The gradient is less clear for chloroplasts, but is equivalent and can be uncovered by nuclear mutations that slow down chloroplast development, such as in slow-greening or virescent mutants (López-Juez et al., 1998). For example in the cue6 mutant, chloroplasts at the leaf tips are undistinguishable from wild type, while those at the flanks closer to the base are essentially proplastids, of small size and very limited extent of development of thylakoids (Fig. 3B).

One spectacular case of interaction between chloroplast biogenesis and leaf development is that of variegated mutants (Aluru etal., 2001; Sakamoto, 2003). Variegation can be caused by defects in core mechanisms in chloroplast biogenesis, due to unstable insertions of transposons in such essential nuclear genes. A more interesting kind of variegation, however, is that caused by stable mutations, which however cause heterogeneous chloroplast deficiency phenotypes. One such variegated mutation, immutans, is caused by a defect in a plastid targeted alternative oxidase (Aluru et al., 2001; Rodermel, 2001). It is postulated that this protein is involved in a carotenoid biogenesis step, in a non-essential way (Carol et al., 1999). However the most commonly identified mutations resulting in variegated plants have been found to define $V A R 1$ or $V A R 2$, genes of the $\mathrm{FtsH}$ protease family. This protease class is required for the disassembly and turnover of photosystem II reaction centre proteins when damaged by reactive electrons generated by excess light (Sakamoto et al., 2003). Once plastid damage occurs, the sector of leaf formed by the clone of cells derived from the cell that was photodamaged will be devoid of chlorophyll. An interesting question is why does the damage take place in such a discrete fashion, when the cells are genetically identical and no satisfactory answer has been found (Aluru et al., 2001; Sakamoto et al., 2003). The variegation occurs when the defect in plastids in a cell takes place very early, when leaf primordia are formed by a very small number of cells. Plastid or cell population factors might play a role. It is possible that the function of this FtsH protein class specifically results in a peculiar type of damage, one that takes place rarely, only in very immature plastids, but that once it has happened, leads to the release of free pigment, for example, this having an autocatalytic effect on the complete damage of that plastid and, if the envelope breaks, possibly of other plastids in that cell. Progress in chloroplast differentiation might reach a point in which the organelle is far more resistant to damage from loss of the protein, so that no new differential plastid/cell clones emerge.

\section{Other plastid types}

Our knowledge of the regulatory networks underlying the conversion of proplastids into other plastid types, like amyloplasts or chromoplasts, is surprisingly limited. We obviously know that plastids differentiate according to the cell type they reside in. For example root plastids in the vicinity of the meristem appear as proplastids, but a few cells in very close proximity, the columella cells of the root cap, accumulate a special type of amyloplast, the statolith, that plays a critical role in gravity sensing (Morita and Tasaka, 2004). Amyloplasts accumulate in potato tubers, proplastids being converted to amyloplasts under the influence of kinetin (Mingo Castel et al., 1991), while light induces the conversion of amyloplasts into chloroplasts (Ljubicic et al., 1998). Amyloplast development is also susceptible to external intervention in suspension cultures of tobacco Bright Yellow-2 cells. Cells of such cultures possess proplastids or undifferentiated leucoplasts, but depletion of auxin and exposure to cytokinin triggers amyloplast formation (Miyazawa etal., 1999). This plastid differentiation has been shown to require the transcription of nuclear genes for starch biosynthesis proteins (Miyazawa et al., 1999), while the plastid genome shows a global decrease both in transcription and in the turnover of mRNA, leading to the paradoxical increase in steady state levels for some transcripts (Sakai et al., 1999). In this sense amyloplasts could be interpreted as proplastids that have become semi-passive recipients of specific nuclear-encoded proteins. Another developmental transformation studied in some detail is that of chloroplasts in green tomato fruits to chromoplasts in ripe fruits. This conversion is accompanied by the fall in expression of photosynthetic nuclear genes, the active degradation of chloroplast photosynthetic proteins and the disassembly of thylakoids (Piechulla et al., 1987). At the same time the expression of carotenoid biogenesis genes increases dramatically (Giovanonni, 2004). Meanwhile, the transcriptional activity of the plastid genome remains virtually unchanged (Marano and Carrillo, 1992). Once again it appears that, in this transition, plastids act as acceptors of proteins expressed under the control of regulatory mechanisms in the nucleus.

\section{Differential plastid development within leaf cells}

A specialised type of plastid differentiation takes place in leaves of species with $\mathrm{C} 4$ photosynthesis, in which the light reactions of photosynthesis and the Calvin cycle have become physically separated into two cell types. The first, mesophyll cells, contain morphologically normal chloroplasts, in whose thylakoids ATP and NADPH are generated and $\mathrm{O}_{2}$ released, but in whose stroma $\mathrm{CO}_{2}$ is fixed into a C4 compound. This compound is transported to bundle sheath cells, closely associated with veins and whose chloroplasts have rudimentary thylakoids and do not release $\mathrm{O}_{2}$, but instead decarboxylate the C4 compound and carry out the Calvin cycle. The differentiation of these two types of cell has been examined intensely in maize. Maize also possesses organs, like husk leaves, in which ordinary $\mathrm{C} 3$ photosynthesis takes place. As would be expected, nuclear genes for the small subunit of Rubisco, the first enzyme in the Calvin cycle, are expressed specifically in C4 bundle sheath cells of normal leaves, as well as in cells of C3 organs (Ewing et al., 1998). Mutations have been identified that disrupt bundle sheath cells specifically. Bundle sheath defective 2 
( $B s d 2)$ encodes a protein required for the post-translational control of the accumulation of the large subunit of Rubisco, its absence leading to defective bundle-sheath chloroplasts (Brutnell et al., 1999). Golden2 (G2), also designated as Bsd1, encodes a nuclear protein with transcriptional regulatory activity and necessary for the differentiation of $\mathrm{C} 4$ bundle sheath chloroplasts. A golden2-like ( $Z m$ G $/ k 1)$ homologue exists in maize and interestingly this gene is differentially expressed in C4 mesophyll cells (Rossini et al., 2001). Given the phenotype of the absence of $G 2$ and the molecular function of $G 2$ and $G / k 1$, it is tempting to speculate that these two genes are activators of the respective kinds of chloroplast development. It is also worth noting that the differentiation of specific chloroplast functions in cells closely associated to vascular bundles has been observed widely, so predating the emergence of C4 species (Hibberd and Quick, 2002).

\section{The control of plastid gene transcription}

As we have seen, during leaf cell differentiation a specific stage is reached during which massive accumulation of photosynthetic complexes takes place. This stage does not occur in non-photosynthetic cells. How is the specific transcription of plastid-encoded, photosynthetic genes achieved? The sequential regulation of RNA polymerases plays a key role (Fig. 3B). NEP activity is first required for housekeeping functions. A knock-out mutant of one of three widely-expressed NEP genes in Arabidopsis, RpoT;2, shows not only delayed greening, but also reduced root and hypocotyl growth and altered leaf shape (Baba et al., 2004). Once NEP function has eventually led to the translation of the PEP chloroplast-encoded subunits, these become more important in the expression of photosynthesis-related proteins. The recognition of PEP promoters requires the activity of sigma factors. Most higher plants contain multiple sigma factors, the Arabidopsis genome encoding 6 genes (Isono et al., 1997; Fujiwara et al., 2000). Plants defective in genes for these factors are revealing differential specificities. Responses to signals, like light cues, are achieved by phosphorylation of sigma factors (Ogrzewalla etal., 2002) and by their differential expression (see below). A knockout of AtSig2 shows defective greening but no deficiency in the production of most photosynthetic protein transcripts. The riddle is explained by the deficiency observed in this mutant in the transcription of IRNAs (Kanamaru et al., 2001). One

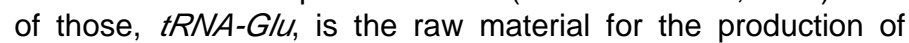
aminolevulinic acid, the first committed precursor in the biosynthesis of chlorophyll and other tetrapyrroles. AtSig2 appears to play a primary role in tRNA transcription. The analysis of a number of other knockout mutants and of the expression patterns of different AtSig genes suggests the following sequence of activities: A general sigma factor, AtSig6, acts on multiple photosynthetic gene promoters in young seedlings (Ishizaki et al., 2004). Its function is gradually taken over by one or more other general sigma factors, probably AtSig3 and AtSig1 (Privat et al., 2003). AtSig5 shows unique properties. It has long been known that the genes $r b c L$, psbA, 165 rrn, (Chun et al., 2001) and psbD (Thum et al., 2001) respond to blue light signals through increased transcription. $p s b D$ is unique in that it can use several promoters, with distinct transcription initiation sites and produces multiple transcripts. One of those transcripts is specifically induced by blue light, from a blue-light responsive promoter (Thum et al., 2001), or by both blue and red light of high fluence (Mochizuki et al., 2004). The response to light is of adaptive significance, as $p s b A$ and $p s b D$ encode the reaction centre of photosystem II, proteins that are easily damaged under excessive light excitation and need to be rapidly turned over. The photoreceptors cryptochromes and phytochrome $A$ are responsible for light sensing and the control of nuclear responses (Thum etal., 2001). The command reaches the plastids through the action of AtSig5, since this sigma factor specifically is expressed in response to light (Tsunoyama et al., 2004), in a very rapid manner (Dillon, Bögre and López-Juez, unpublished observations) and also responds to a number of stresses that in nature compound the propensity to photodamage (Nagashima et al., 2004). The control is therefore elegantly simple: a photoreceptor with action in the cell nucleus activates the transcription of a specific sigma factor and
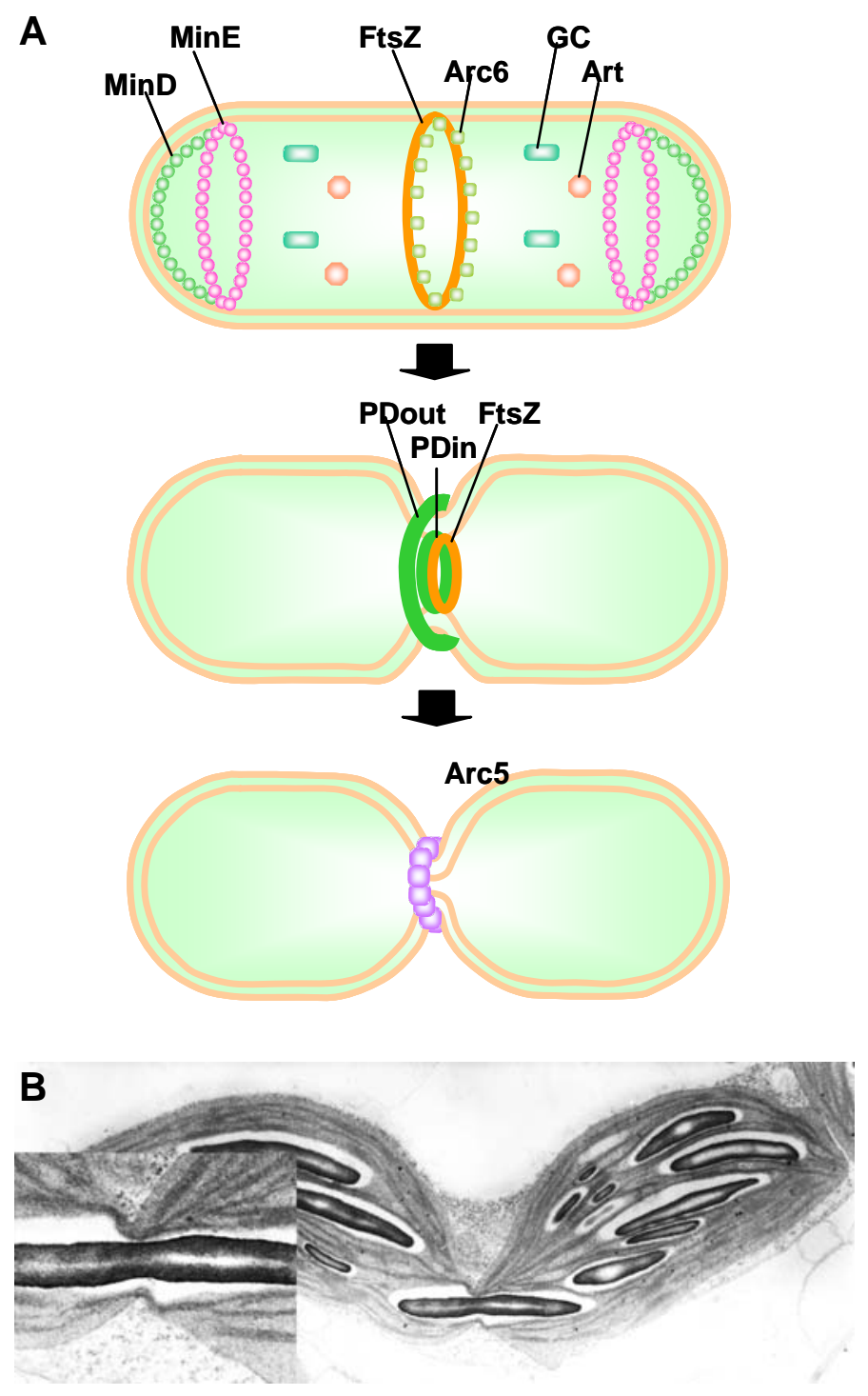

Fig. 5. Plastid division. (A) Plastid division process and role of several known components of the division machinery. PDout, plastid division ring, outer; PDin, plastid division ring, inner; GC, giant chloroplast; Art, Artemis. (B) Chloroplasts arrested in incomplete division by physical interference caused by a long, narrow starch rod. The left inset shows the starch rod apparently being subjected to constriction from the plastid division and associated rings. 
this factor, targeted to the chloroplast, acts as a co-factor of the plastid RNA polymerase and activates the transcription of a plastidencoded gene (Fig. 3B).

\section{Differentiation by control of protein import?}

It is possible for the variety of plastids in different cells to result not only from the differential expression of each of the various nuclear-encoded genes for plastid proteins, but by differences in the basic mechanisms of plastid build-up, particularly plastid protein import. In pioneering work, Wan and coworkers (1996) demonstrated that seed 'leucoplasts' and leaf chloroplasts imported individual proteins differentially, the efficiency for each protein being related to the actual in vivo abundance of the protein in each plastid type and that the differences were specified by each protein's transit peptide. Evidence that this phenomenon is explained by the differential composition of the import machinery is now accumulating. As discussed earlier, most components of the Toc and Tic complexes are encoded by small gene families in Arabidopsis. Individual gene family members may encode proteins with slightly different functions. This is particularly the case for Toc159 and Toc34, which together act as receptors gating the outer envelope pore and therefore control which proteins are or are not allowed passage. Loss of atTOC159 or of atTOC34, both leading to significant or extreme defects in greening, causes no obvious effect in root cells, or even in guard cells (Yu and Li, 2001). Meanwhile Kubis et al. (2004) and Ivanova et al. (2004) have observed that reducing or knocking out expression of atTOC132 and atTOC120, the two other alternative members of the Toc159 family, which result in chloroplast phenotypes only when both are fully knocked-out, bring about a defect also in root plastids and cause altered root growth. Similarly a defect in atTOC34, the homologue of atTOC33, causes deficient root plastids and a 20$30 \%$ reduction in root growth, but does not lead to pale leaves, indicating a predominant photosynthetic role for atToc33 and a house-keeping or root-plastid role for atToc34 (Constan et al., 2004). These specificities must help avoid competition for import sites by proteins expressed at very different levels in developing chloroplasts, but are also likely to be part of the various differentiation programmes, a notion that the various patterns of gene expression by tissue type is consistent with. Two interesting sets of observations were those of Kubis et al. (2003, 2004) who monitored protein accumulation and gene expression for a number of photosynthesis-associated or unrelated chloroplast proteins. Defective atToc132, which is devoted to import of non-photosynthetic proteins, led to both reduced accumulation of those proteins and to lower expression of their genes, while loss of atToc33, which imports photosynthetic proteins, resulted in decreases in photosynthetic protein accumulation and gene expression. A consequence is that changes initiated by an altered balance of the two forms for each subunit of the receptor will have an autocatalytic impact: as a reduced amount of photosynthetic proteins is imported, less transcription of their genes will take place, gradually amplifying the difference.

\section{The regulation of plastid proliferation}

The accumulation of a full complement of chloroplasts in mature leaf cells must involve a large, regulated extent of plastid DNA replication and plastid proliferation. This has been observed in expanding Avena leaves (Hashimoto and Possingham, 1989a), cultured spinach leaf discs (Hashimoto and Possingham, 1989b), or young pea leaves cultured in the light (DuBell and Mullet, 1995a). Distinct levels of regulation can be deduced from the fact that various stages of the process can become uncoupled. For example the duration of morphological stages of plastid division in expanding leaf discs has been carefully measured, with the conclusion that in the dark one particular stage, the transition from initiation of division (visualised as a dumbbell shape) to its conclusion is particularly extended (Hashimoto and Possingham, 1989b). The most important level of regulation is that by which the extent of plastid division is adjusted to the size of the cell in which it happens. Chloroplast number per cell and cell size are closely correlated (Possingham and Lawrence, 1983; Cookson et al., 2003). When mutations preventing chloroplast division could disturb this correlation, the area of the cell occupied by the chloroplast/ chloroplasts will remain constant (Pyke, 1997). Similarly, when a cell cycle regulator is engineered in a way that it decreases cell division and causes cell enlargement of over one order of magnitude, the chloroplasts multiply and the density of chloroplasts per area remains constant (Jasinski et al., 2003). Thus a tight control of 'chloroplast compartment size' exists. The primary consequence of this is that photosynthetic cells will always possess one layer, and only one, of chloroplasts occupying around $70 \%$ of the area of the cytoplasm, appressed between the vacuole and the cell membrane. When environmental conditions such as high light lead to elongation of palisade cells into a more columnar shape, the chloroplasts will multiply to the extent of occupying this new space available (Pyke and López-Juez, 1999) (Fig. 2 C,D). This is evidence that chloroplast division initiation responds to a cellular parameter dependent on cell size, for example the absolute amount of a cytoplasmic component. It is interesting to note that the correlation occurs between the area occupied by plastids and the plan area of the cell, rather than the relative volumes, as might have been assumed (see Pyke, 1999). This would, at face value, indicate that a two-dimensional parameter, for example a factor associated with the plasma membrane, reports the cell size, but it may also result from the fact that leaf cells are largely thin layers of cytoplasm appressed between the tonoplast and the plasma membrane and that the increase in cytoplasm as cells expand occurs essentially in two dimensions. In yeast, entry into the cell cycle is critically controlled by cell size and the absolute level of specific G1 phase cyclins, among other proteins, a level that increases in line with general growth and protein accumulation, determines the critical size at which division occurs (Zhang et al., 2002); however even in this case the detailed mechanisms are poorly understood. In plants, an uncoupling of plastid compartment and cell size has been observed in mutants altered in light responses, such as the hp1 and hp2j mutants in tomato (Cookson et al., 2003; Melian and López-Juez, unpublished observations). The targets for this regulation are also largely unknown but appear to include FtsZ since expression of Fts $Z$ has been shown to increase when dark-grown cotyledons of pumpkin are exposed to cytokinins or light, inducing multiplication of plastids and conversion of etioplasts into chloroplasts (Ullanat and Jayabaskaran, 2002) and also shows a degree of up-regulation when synchronously-growing tobacco cell cultures undergo the mitotic phase (El-Shami et al., 2002). Increases under related dark-light transitions can be observed in Arabidopsis, for FtsZ1, MinD and Arc5 (Dillon, Bögre and López-Juez, unpublished results). The regula- 
tion of Arc5 would be consistent with the accumulation of incompletely divided plastids in the dark. In spite of all this, each of these targets play mechanical, rather than regulatory, roles in plastid division and it is unlikely that they explain the global control perse. An ability to intervene in this global regulation and alter the size of the plastid compartment per cell, would have consequences in plant biotechnology that would be difficult to underestimate.

\section{Plastids/chloroplasts are under environmental control}

\section{Photoreceptors and chloroplast development}

As mentioned earlier, environmental signals can control responses like patterns of chloroplast gene expression, as in the $p s b D$ blue light responsive promoter. The most extreme such case is the control by light of the differentiation of distinct plastid types: proplastids are converted into etioplasts in the absence of light, while cotyledon etioplasts (and to some extent tuber amyloplasts) rapidly differentiate into chloroplasts in the light. Etioplast development allows a degree of membrane build-up and very large accumulation of the chlorophyll precursor protochlorophyllide, in a form, bound to protochlorophyllide reductase (POR), that makes it ready to be photoconverted by light, without causing photooxidative damage. A specific form of POR, encoded by the PORA gene, has evolved for this process (Armstrong et al., 1995). In normal, light-grown leaf tissue, a second form of POR encoded by the PORB gene plays the predominant role and PORB is constitutively expressed. Expression of the PORA gene, on the other hand, is very high in the dark, but is light-repressed and the protein itself, key component of the prolamellar body, is light labile (Armstrong et al., 1995).

The conversion of etioplasts into chloroplasts involves a far greater number of components, in essence as many as are required to build chloroplasts from proplastids. The light signals are perceived by two main classes of plant photoreceptors, phytochromes (of broad spectral sensitivity, but primarily for red light) and cryptochromes (for blue-ultraviolet A light). The function of phytochromes and cryptochromes is described elsewhere in this issue. Upon light sensing by dark-grown seedlings, a vast number of nuclear genes, between a few \% and over $10 \%$ (depending on threshold) of the total plant genome changes in expression and about half of the genes whose expression is elevated encode chloroplast proteins (Ma etal., 2001; Tepperman et al., 2001). Two long-studied such genes are $L$ hcb1, for the major granal thylakoid protein associated to photosystem II and $R b c S$, for the small subunit of Rubisco (Kuno and Furuya, 2000). A large number of components involved in signalling events downstream of photoreceptors are known, as also discussed in detail elsewhere in this issue. One key aspect is the function of repressors of photomorphogenesis, all identified by mutations that allowed photomorphogenesis to occur in the absence of light. These repressors include the De-etiolated 1 gene product (DET1), the Constitutively phomotomorphogenic 1 product (COP1) and the COP9 and other members of the COP9 'signalosome', which either remodel chromatin or target effectors of light responses for proteolysis (Schäfer and Bowler, 2002; Wang and Deng, 2003). DET1 and COPs mediate global light responses, so are not specific for genes for chloroplast proteins. The fact that it is possible to prevent the light induction of $L h c b 1$ or $R b c S$ without altering other light responses, including the induction of genes for non-chloroplast proteins (López-Juez etal., 1996; Lin and Cheng, 1997; López-Juez et al., 1998; Vinti et al., 2005) suggests that mechanisms that act upon light perception and specifically activate chloroplast development should exist, but no such mechanism has been identified to date.

Are these light-response mechanisms of relevance when attempting to understand chloroplast development? It has been argued that etioplasts are to some extent artificial plastids, a product of the unnatural conditions that plant scientists can expose plants to, in this case extended germination in the dark. In nature most leaf chloroplasts will have been built from meristem proplastids, without ever arresting at an etioplast stage. However, the conditions do arise, as evidenced by the fact that plants have evolved PORA and DET1. Furthermore, for the same reason that

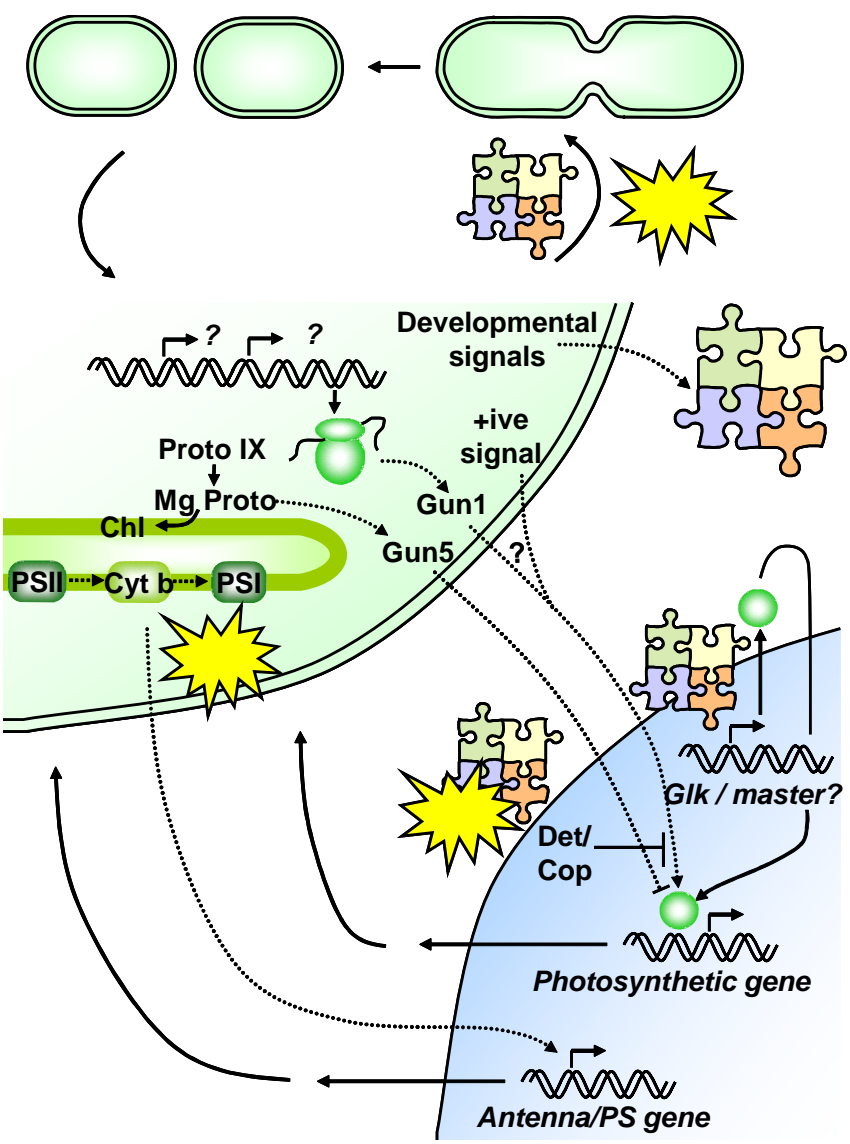

Fig. 6. Regulatory networks that influence plastids/chloroplasts and integrate their development into the cell's biology. Developmental (jigsaw symbol) and environmental (star symbol) influences are indicated. The plastids themselves emit signals that feedback onto those networks, or may in some cases mediate them. For interactions relating to the expression of the plastid genome, see Fig. 3. Where indicated (?), the nature or role of signals or their mode of interaction is hypothetical. The redox-type chloroplast signal (emanating from Cyt b) can have positive or negative effects, depending on the target gene. Evidence exists for other redox-type signals. Target genes (antenna/photosystem genes) are a subset of photosynthetic genes. +ive, positive; Chl, chlorophyll; Cyt b, cytochrome $b_{6} f ; M g$ Proto, magnesium protoporphyrin; ProtolX, protoporphyrin IX; PS, photosystem. See text for other details. 
light regulates the expression of genes like Fts $Z$, it is reasonable to assume that the simplest way for plants to impose repression upon responses the avoidance of which in the dark is of adaptive value, would be to repress the operation of master agents of such responses. In other words, their environmental regulation may be the flag that allows the identification of such agents (Fig. 6).

\section{Photosynthetic redox signals and chloroplast development}

Presence or absence is not the only feature of the light environment that plants are exposed to and, consequently, that plastids respond to. Differences of two orders of magnitude in light intensity (fluence rate) and changes in quality (proportion of light of different spectral regions) occur through the life of a plant emerging through a canopy, during the day, as solar radiation filters through into sunflecks and even at any given moment, within the same organism, when considering leaves exposed at the exterior of the canopy or buried deep inside. This is particularly important for chloroplasts, as they need to capture this light while avoiding its harmful consequences. Rapid, biophysical and biochemical mechanisms for acclimation of the photosynthetic apparatus to the light environment, taking place in a timescale of milliseconds to minutes, have been intensely studied (Ort, 2001). One of them, the redistribution of antenna complexes, explains the organisation of thylakoid membranes described earlier. Also mentioned above were mechanisms of adaptation that involve chloroplast movement, towards weak light or away from strong light. Of greater interest here, the development of both chloroplasts and leaf cells harbouring them responds in an adaptive way to these changes (reviewed by Anderson et al., 1995; Vogelmann, 2002). These responses occur in a timescale of minutes to days. Chloroplasts grown under intense light contain reduced levels of photosynthetic antenna complexes, while the relative proportion of both reaction centres and energy-utilising, Calvin cycle enzymes is increased. The converse takes place in shade-grown plants. As a consequence, chloroplast ultrastructure changes, with granal thylakoids in chloroplasts developed in shade increasing in number of stacks and in the proportion of the area they occupy in chloroplast sections (Anderson, 2000; Weston et al., 2000) (Fig. 2C). The relative changes in protein accumulation, the clearest of which is the reduction in Lhcb antenna under high light (Weston et al., 2000) are a consequence of a reduction in expression for $L h c b$ genes under high light (Escoubas et al., 1995). In parallel to these chloroplast changes, mesophyll cells show pronounced responses (Vogelmann, 2002), Under high light palisade cells extend in length and may divide into multiple layers, allowing a single light ray to transverse and be attenuated by, a much greater number of chloroplasts.

What is the perception mechanism for the fluence rate of light? Some of the photoreceptors controlling the etioplast to chloroplast conversion have good properties as light quantity sensors. Some of the acclimation responses are particularly sensitive to blue light (Sawbridge et al., 1994; López-Juez and Hughes, 1995) and the fact that Arabidopsis plants show robust acclimation responses (Walters and Horton, 1994) has allowed the hypothesis that they play a role to be tested. However, cryptochrome and phototropin null mutants (Weston et al., 2000; López-Juez et al., unpublished) still show changes in the accumulation of Lhcb, in the ultrastructure of chloroplasts and in the development of palisade cells that are indistinguishable from the wild type. What does appear to play a key sensory role is the photosynthetic apparatus itself, that is, redox processes taking place inside the chloroplasts under high light are sensed by the nucleus to modulate the expression of $L h c b$ genes (Escoubas et al., 1995; Pfannschmidt et al., 1999). Earlier experiments had shown that photoreduced plastoquinone, which accumulates under high light, activates through the action of an Lhcb kinase the movement of Lhcb between the PS and from the granal to the stromal thylakoids. Similar experiments now showed that the same signal could regulate $L h c b$ gene expression in the nucleus (Escoubas et al., 1995). More precisely, the acceptor of reduced plastoquinone, the cytochrome b6f complex, has been proposed as the source of the signal (Allen 2004). The same signal can be generated by imbalances in the light absorbed by both PS, since sun light tends to excite PS II preferentially over I. Importantly, this signal produced by such light imbalances, is capable of very rapidly regulating the relative expression of plastid genomeencoded genes for PSII and PSI (Pfannschmidt et al., 1999; Pfannschmidt, 2003). Thus, redox signals regulate the expression of chloroplast-encoded genes and, as discussed earlier, could even explain the retention of such genes in a plastid genome. They also result in the relay of a signal to the cell's nucleus that regulates the expression of nuclear genes for other photosynthetic proteins. In other words, they result in 'plastid autoregulation'. Although we have focused on light acclimation, one consequence of the source of the regulatory signal is that it would be generated by any other environmental circumstance that resulted in excess generation of highly energised electrons, for example low temperature or water deficit, both slowing down the utilisation of such electrons. Indeed similar 'autoregulation' of chloroplast composition operates under such circumstances (Pfannschmidt, 2003).

Beyond the postulated source of the signal, little is known about this plastid redox signalling mechanism. Widespread in eubacteria, a member of the two component His kinase sensory family, the RegB/RegA system, regulates many redox-dependent responses (Elsen et al., 2004). Specifically in cyanobacteria, redox regulation of the genes for polypeptides for the two reaction centres does occur and is mediated by the two component RppB/RppA system (Li and Sherman, 2000). For such a mechanism to operate in chloroplasts, the sensor would need to be physically in contact with thylakoids, where signals arise. However a survey of the 17 obvious His kinases encoded by the Arabidopsis genome, using TargetP, shows none of them to have a predicted chloroplast targeting sequence. The search must continue through multiple avenues. One such avenue is that of thioredoxin function. Thioredoxins are redox-regulated proteins that receive electrons from photosynthesis, albeit from the terminal point, ferredoxin and which in turn regulate other processes, like the translation of the plastid mRNA for psbA (Bruick and Mayfield, 1999). Different classes of thioredoxins occur in the plastid and the cytoplasm, the later being potentially able to modify nuclear factors. It has been speculated that thioredoxins might mediate their own redox plastid signalling pathway (Pfannschmidt, 2003). A separate, highly promising avenue, is using a genetic approach (Walters et al., 2003).

\section{Further plastid autoregulation: convergence of signals?}

It is not just the redox state of the photosynthetic electron transport chain that generates plastid signals controlling nuclear gene expression. A separate signalling process of even more 
dramatic consequences was first uncovered by the analysis of cereal mutants with defective plastids. The barley mutant albostrians, with alternating stripes of green and white tissue, contains no detectable ribosomes in chloroplasts of white cells and fails to synthesise enzymes destined for the plastid but encoded by the nucleus (Bradbeer et al., 1979). Maize mutants also exist with defects in enzymes of carotenoid biogenesis. Carotenoids play a number of photoprotective functions in chloroplasts. When such mutants are grown under moderately high light, extensive photooxidative damage to the plastids occurs. In such circumstances the expression of Lhcb genes ceases (Mayfield and Taylor, 1984). Similar observations have been made for other photosynthesisassociated nuclear genes and using several treatments conducive to plastid damage (Oelmüller et al., 1986). Work since has vastly extended the number of genes known to be plastid signal regulated and shown in a number of cases that promoter-reporter fusions are plastid-sensitive, i.e., that the regulation is transcriptional (Rodermel, 2001). Interestingly, a gene like Nitrate Reductase 2, encoding a protein that is cytosolic but depends on photosynthetic reducing power, is plastid status-sensitive, while PORA, which encodes an abundant etioplast protein, is not plastid signal-dependent. This suggests that the fitness value driving the evolution of plastid signalling may have to do, in part at least, with protection from the secondary effects of plastid photodamage (Vinti et al., 2005). It is also worth pointing that two main categories of treatments affecting plastids have been used, those that cause photobleaching, secondary to the loss of carotenoids (through mutations or the use of the carotenoid biosynthesis inhibitor norflurazon) and those that block plastid genetic activity (through translation inhibitors, like lincomycin or chloramphenicol, the use of transcription or DNA gyrase inhibitors, or through the albostrians mutation). These treatments can be distinguished in two ways: norflurazon treatment will shut-down photosynthetic gene expression whenever photobleaching happens, while translation or transcription inhibition have to be applied very early in seedling development (first 23 days) for their effect to take place (Gray et al., 2002). They are also conceptually different, in that photobleaching can more easily lead to the production of a warning signal, with a negative effect on gene expression, while absence of transcription/translation is more likely to prevent the production of a signal, which in this case would be a positive regulator of photosynthetic genes.

A crucial step towards the identification of the nature of plastid signals took place through the identification of Arabidopsis mutants in which the expression of a norflurazon-sensitive promoter, Lhcb1, remained partly 'on' even when the plastids were damaged (Susek et al., 1993). These mutants were named genome uncoupled (gun). Five gun loci exist. Genetic analysis, as well as the analysis of their genetic interaction with a phytochrome chromophore-defective mutant ( $h y 1)$, have revealed that some of them act on two separate pathways, one of them involving tetrapyrrole biosynthesis (Mochizuki et al., 2001; Vinti et al., 2000). A direct negative regulatory effect of tetrapyrrole accumulation on $L$ hcb gene expression has also been observed (Vinti et al., 2000; La Rocca et al., 2001). The tetrapyrrole biosynthesis pathway produces as its two main terminal products chlorophyll and haem. These are distinguished by the metal they have bound, iron in haem and $\mathrm{Mg}$ in chlorophyll. GUN5 encodes a regulatory subunit of the enzyme in the Mg-chelating step (Mochizuki et al., 2001). Subsequent analysis has provided evidence for Mg-proto- porphyrin to accumulate upon plastid damage and act as a negative signal on $L h c b 1$ expression (Strand et al., 2003). The GUN2 through GUN5 genes operate in this pathway. It has, therefore, been postulated that GUN1 acts in the second regulatory pathway, which depends on plastid transcription/translation, based on the fact that only gun1 shows a gun response to treatment with lincomycin (Gray et al., 2002).

\section{A unifying signal?}

Extensive promoter analysis has been carried out for at least five unrelated plastid signal-dependent genes. In all cases the minimal promoter region identified as being able to direct plastidsensitive transcription also led to transcription in the light, but not in the dark, that is, plastid signal and light appear to operate through the same promoter elements (Strand, 2004). One case, the promoter of rice sucrose phosphate synthase gene, central in the production of sucrose, showed differential behaviour depending on the tissue: it was found to direct reporter expression in a way that was light-regulated and dependent on plastid status in photosynthetic tissues, while in seed scutellum it is independent of both light and plastid signals (Chávez-Bárcenas et al., 2000). Mutations causing strong defects in plastid development have been shown to result in a specific loss of the ability to respond to activation by phytochrome and this has led to the proposal that phytochrome utilises plastid-signalling mechanisms to control the expression of genes for chloroplast proteins (López-Juez et al., 1998; Vinti et al., 2005). Plastid signalling mechanisms predated the emergence of light responses for photosynthetic genes (Kojima et al., 1994; Hills, 2002). Mutations in the repressors of light responses, DET1 and COP1, cause expression of genes for photosynthetic proteins in the dark, but this expression is sensitive to mutations causing defective plastids in the dark, that is, in double mutants $L h c b$ expression is lower than it is when plastids are functional (Hills and López-Juez, unpublished results). A simple model accounting for these observations is that $L h c b$ is responsive primarily to a plastid-generated signal. This response is repressed by DET1/COP1 and that repression is, in turn, relieved by light.

It is interesting that the analysis of the det1 mutant has revealed chloroplast development not only in the dark (albeit chlorophyll-less), but also in root cells (Chory and Peto, 1990). Is it the case that a primary, positive plastid signal exists that drives the expression of genes for photosynthesis and the biogenesis of chloroplasts and that the action of this signal is repressed by DET1-like action both in roots and in the dark? This is an intriguing possibility. A prediction of this model would be that identification of promoter elements mediating one of the responses should show all three. This is indeed the case in one promoter in which it has been examined: computational analysis helped define the smallest known light-regulated promoter element, called CMA5, mediating the response of a tobacco RbcS gene (ArgüelloAstorga and Herrera-Estrella, 1998). Dimers of CMA5 are capable of driving GUS reporter expression in the light and not in the dark, the expression in the light is sensitive to norflurazon and no expression is observed in roots (Martínez-Hernández et al., 2002).

Like any 'unifying theory', this model is very attractive but could be dangerously oversimplified. In spite of this, such 'master regulator' is being actively sought and candidates have already 
been proposed: Golden2 and Glk genes are a family of transcriptional regulators widely distributed in plants, whose mutations cause defective chloroplast development, correlative to their expression patterns and which are not present in cyanobacteria, implying their role is not intrinsically required for photosynthesis (Fitter et al., 2002). It is also possible to design genetic screens for such a positive regulator of chloroplast development. Arabidopsis in vitro-grown callus, containing undifferentiated proplastids, has been transformed with a selectable marker driven by an RbcS promoter. Without intervention, activity of the promoter remains off and the callus does not survive selection. Such callus has been subjected to a programme of random insertion of an enhancer element (activation tagging). This has resulted in the isolation of one mutant callus with an active RbcS promoter. The gene activated by the enhancer belongs to the family of plant transmembrane receptor kinases (Goto et al., 2004; Y. Niwa and $\mathrm{H}$. Kobayashi, personal communication), a large, diversified group of genes, some of whose members mediate cell-communication and developmental responses. Unfortunately, overexpression of this gene was able to recapitulate the expression of $R b c S$ in callus but not in plant root cells. However such an elegant search for a 'chloroplast master regulator' seems exceptionally promising.

\section{Plastids are sources of developmental signals}

We have examined the mechanisms by which, after integration of the ancestral endosymbiont into the host cell, plastid biogenesis occurs, often under the control of signals from the 'captor'. The 'captive' organelle, however, has not only contributed vastly to the genomic resources of the host, in evolutionary terms. Evidence is rapidly accumulating that even at present the organelle exerts great developmental influence over the cell that hosts it.

Evidence for the existence of plastid developmental signals derives from the analysis of variegated mutants. In Arabidopsis immutans, clear-cut sectors containing only functional or only dysfunctional plastids exist next to each other. In white sectors not only are plastids defective, but also the anatomy of the leaf is altered and a cross section shows very poor development of a palisade cell layer (Aluru et al., 2001). This phenomenon is not unique to immutans. The Antirrhinum DAG mutant (Chatterjee et al., 1996) is disrupted in a gene, homologues of which appear involved in ribosomal RNA maturation (Bisanz et al., 2003). Without DAG, plastids remain in the proplastid stage and tissue remains white, but presents revertant sectors in which normal chloroplasts develop. In these sectors and only in these, normal palisade cell development takes place (Chatterjee et al., 1996). The equivalent phenotype is observed in a mutant defective in the Arabidopsis DAG-like ( $D A L$ ) gene. Similarly a mutation in the tomato DCL (defective chloroplasts andleaves) gene, necessary for the correct processing of plastidic 4.5 S rRNA (Bellaoui and Gruissem, 2004) lead to the double defect in chloroplasts and in palisade cell morphogenesis that its name indicates (Keddie et al., 1996). Cells, in given cell layers, with ribosome-free plastids can also be generated simply by extended growth on spectinomycin, a plastid translation inhibitor (Pyke et al., 2000). Such cells again do not show palisade differentiation.

Variegated mutant plants are chimeras of cell lines with mutant and wild type plastids. When the loss of plastid function is more extensive and takes place early on, it has more dramatic consequences. Kuroda and Maliga (2003) have generated plants with engineered plastid genome (transplastomic) in which the $c / p P$ gene was converted into a form ready to be removed by recombination. When the corresponding recombinase was introduced by crossing the transplastomic plants with pollen from recombinaseexpressing ones, the progeny contained seedlings in which the loss of $c / p P$ had taken place and these seedlings not only were albino, they showed complete loss of shoot tissue apart from the cotyledons. It may be argued that such shoots are lost, or that mutant sectors in variegated genotypes have defective palisade cell division and differentiation, because their plastid defect starves the cells of essential biomolecules. Although this indirect explanation cannot totally be ruled out, it is probably insufficient, as products of nuclear genes carry out most plastid metabolic activities, with the exception of photosynthesis. Starvation of photosynthate is not sufficient explanation either. Ahlert and coworkers (2003) have constructed transplastomic plants containing a gene conferring resistance to a chloroplast translationinhibiting antibiotic, in an unstable form that can be lost by spontaneous recombination. Growth of these plants on the antibiotic led not to white sectors, but to the complete loss of regions of leaves. Growth of the plants without the antibiotic, followed by transfer onto it after leaves had formed, led to the formation of white, but live, sectors, showing that the earlier translation inhibition had actually prevented cell division. The fact that this took place adjacent to normally-growing sectors and also in flower petals, which are not photosynthetic, demonstrates that this phenomenon is caused by the loss of a plastid function needed for cell division and development, or by loss of a biomolecule that cannot be shared across tissues, rather than by loss of photosynthesis. Were a signalling mechanism to be the explanation, whether this is a consequence of the signalling process between the plastid and nuclear genes for plastid-targeted proteins, or a direct developmental signal of plastid origin (and if so, what the nature of such signal is) is totally unknown. One recently identified gene, CRUMPLED LEAF (Asano et al., 2004) might be involved in the production or export of such a developmental signal, as it encodes a chloroplast envelope protein, absence of which causes defective chloroplast division and also aberrant cell plane division and cell differentiation.

Early seedling development appears to be particularly sensitive to the loss of plastid function. In an extensive screen for seedling lethal mutants that identified 496 Arabidopsis lines, Budziszewski et al. (2001) found that $84 \%$ of the mutations caused seedlings with an albino or pale phenotype. This gives a measure of the extensive number of genes whose products play a role in plastid biogenesis and the importance that this process has for cell survival. Of interest is the fact that, among 22 lines whose mutated locus was identified, three encoded enzymes in the non-mevalonate chloroplast pathway of isoprenoid biosynthesis. These included the $C L A 1$ locus, encoding the first enzyme in the pathway (Estévez et al., 2000). The cla1 mutation causes dramatic defects in chloroplast development and in the organisation of leaf palisade tissue. Etioplasts appear to also be abnormal (Estévez et al., 2000). Pharmacological inhibition of isoprenoid biogenesis through this pathway also results in a similar phenotype of seedling arrest (Rodríguez-Concepción et al., 2001). Whether this is a mere result of the metabolic deficiencies caused by photobleaching and the 
loss of plastid activity, or it points to an additional developmental role of this pathway specifically, remains to be seen. A recent search for 'chloroplast biogenesis' ( $c / b)$ mutants, severely chlorophyll-deficient (Gutiérrez-Nava et al., 2004), has revealed that for some of them, including one with a mutation in the plastidial isoprenoid biogenesis pathway, embryo defects ensue. A degree of rescue of the embryos took place when maternal tissues were wild type (demonstrating non-cell-autonomy of the defect). This showed that even lipophyllic biomolecules of plastid origin can be shared across tissues. However other $c / b$ mutants exhibited embryo deficiencies that remained strictly cell-autonomous, again pointing to the likelihood of plastids as sources of essential, developmental signals.

\section{Concluding remarks}

From the above overview it is possible to grasp the vast contribution that the original photosynthetic prokaryote, the chloroplast ancestor, made to the eukaryotic host and to what extent the whole of the biology of the plant is devoted to building this organelle and maintaining its performance. The original chloroplasts have since become targets of developmental signals, differentiating according to the specific cell type they reside in, but they are also agents of development, these functions requiring complex regulatory networks. It is surprising that, in the 'postgenomic' era, we are capable of precisely dissecting the discrete roles of individual members of gene families involved in key plastid biogenesis processes, but some fundamental processes of the biology of plastids in cells have barely started to be unravelled. What are the basic mechanisms of plastid differentiation? Are plastid conversions 'passive' from the plastid point of view and what are the nuclear regulators? What activates plastid division and what stops it once the full pre-established plastid complement of the cell has been reached? Why do cells without functional plastids cease to divide, even when they adjoin cells producing any essential metabolites? How many signals of plastid-nuclear communication exist? Is there a 'chloroplast masterswitch'?

Plastid genetic engineering has also been possible in higher plants since Maliga and collaborators established the technology in the early $90 \mathrm{~s}$, but the range of plants in which it is possible is still exceptionally limited (Maliga, 2003). The potential of this technology is hard to underestimate (Kumar et al., 2004). A greater understanding of plastid developmental mechanisms can only help converting it into a reality.

\section{Acknowledgements}

We are grateful to Dr. Yasuo Niwa and Prof. Hirokazu Kobayashi for sharing unpublished results with us and to Drs. Paul Jarvis and Makoto Fujiwara for critically evaluating parts of the manuscript. Work in the laboratory of ELJ has been or is funded by BBSRC and that in the laboratory of KP by BBSRC and the Gatsby Charitable Foundation.

\section{References}

ABDALLAH, F., SALAMINI, F. and LEISTER, D. (2000) A prediction of the size and evolutionary origin of the proteome of chloroplasts of Arabidopsis. Trends Plant Sci. 5: 141-142.

AHLERT, D. RUF, S. and BOCK, R. (2003) Plastid protein synthesis is required for plant development in tobacco. Proc. Natl. Acad. Sci. USA 100: 15730-15735.
ALLEN, J.F. (2003) The function of genomes in bioenergetic organelles. Phil. Trans. R. Soc. Lond. B Biol. Sci. 358: 19-38.

ALLEN, J.F. (2004) Cytochrome $b_{6} f$ : structure for signalling and vectorial metabolism. Trends Plant Sci. 9: 130-137.

ALLISON, L.A., SIMON, L.D. and MALIGA, P. (1996) Deletion of rpoB reveals a second distinct transcription system in plastids of higher plants. EMBOJ.15:28022809.

ALURU, M.R., BAE, H., WU, D.Y. and RODERMEL, S.R. (2001) The Arabidopsis immutans mutation affects plastid differentiation and the morphogenesis of white and green sectors in variegated plants. Plant Physiol. 127: 67-77.

ANDERSON, J.M. (2000) Insights into the consequences of grana stacking of thylakoid membranes in vascular plants: a personal perspective. Aust. J. Plant Physiol. 26: 625-639.

ANDERSON, J.M., CHOW, W.S. and PARK, Y.I. (1995) The grand design of photosynthesis: Acclimation of the photosynthetic apparatus to environmental cues. Photosynth. Res. 46: 129-139.

ARGUELLO-ASTORGA, G. and HERRERA-ESTRELLA, L. (1998) Evolution of lightregulated plant promoters. Annu. Rev. Plant Physiol. Plant Mol. Biol. 49: 525-555.

ARMSTRONG, G.A., RUNGE, S., FRICK, G., SPERLING, U. and APEL, K. (1995) Identification of NADPH:protochlorophyllide oxidoreductases A and B: A branched pathway for light-dependent chlorophyll biosynthesis in Arabidopsis thaliana. Plant Physiol. 108: 1505-1517.

ASANO, T., YOSHIOKA, Y., KUREI, S., SAKAMOTO, W., SODMERGEN and MACHIDA, Y. (2004) A mutation of the CRUMPLED LEAF gene that encodes a protein localized in the outer envelope membrane of plastids affects the pattern of cell division, cell differentiation and plastid division in Arabidopsis. Plant J. 38: 448459.

BABA, K., SCHMIDT, J., ESPINOSA-RUIZ, A., VILLAREJO, A., SHIINA, T., GARDESTROM, P., SANE, A.P. and BHALERAO, R.P. (2004) Organellar gene transcription and early seedling development are affected in the rpoT;2 mutant of Arabidopsis. Plant J. 38: 38-48.

BAUER, J., CHEN, K.H., HILTBUNNER, A., WEHRLI, E., EUGSTER, M., SCHNELL, D. and KESSLER, F. (2000) The major protein import receptor of plastids is essential for chloroplast biogenesis. Nature 403: 203-207.

BAUMGARTNER, B.J., RAPP, J.C. and MULLET, J.E. (1989) Plastid transcription activity and DNA copy number increase early in barley chloroplast development. Plant Physiol. 89: 1011-1018.

BELLAOUI, M. and GRUISSEM, W. (2004) Altered expression of the Arabidopsis ortholog of $D C L$ affects normal plant development. Planta 219: 819-826.

BENDICH, A.J. (2004) Circular Chloroplast Chromosomes: The Grand Illusion. Plant Cel/ 16: 1661-1666.

BISANZ, C., BEGOT, L., CAROL, P., PEREZ, P., BLIGNY, M., PESEY, H., GALLOIS, J.L., LERBS-MACHE, S. and MACHE, R. (2003) The Arabidopsis nuclear DAL gene encodes a chloroplast protein which is required for the maturation of the plastid ribosomal RNAs and is essential for chloroplast differentiation. Plant Mol. Biol. 51: 651-663.

BLANKENSHIP R.E. (2001) Molecular evidence for the evolution of photosynthesis Trends Plant Sci. 6: 4-6.

BRADBEER, J.W., ATKINSON, Y.E., BORNER, T. and HAGEMANN, R. (1979) Cytoplasmic synthesis of plastid polypeptides may be controlled by plastidsynthesized RNA. Nature 279: 816-817.

BRAMLEY, P.M. (2002) Regulation of carotenoid formation during tomato fruit ripening and development. J. Exp. Bot. 53: 2107-2113.

BRUICK, R.K. and MAYFIELD, S.P. (1999) Light-activated translation of chloroplast mRNAs. Trends Plant Sci. 4: 190-195.

BRUTNELL, T.P., SAWERS, R.J.H., MANT, A. and LANGDALE, J.A. (1999) BUNDLE SHEATH DEFECTIVE2, a novel protein required for post-translational regulation of the rbcL gene of maize. Plant Cell 11: 849-864.

BUDZISZEWSKI, G.J., LEWIS, S.P., GLOVER, L.W., REINEKE, J., JONES, G., ZIEMNIK, L.S., LONOWSKI, J., NYFELER, B., AUX, G., ZHOU, Q., MCELVER, J., PATTON, D.A., MARTIENSSEN, R., GROSSNIKLAUS, U., MA, H., LAW, M. and LEVIN, J.Z. (2001) Arabidopsis genes essential for seedling viability: Isolation of insertional mutants and molecular cloning. Genetics 159: 1765-1778.

BUNGARD, R.A. (2004) Photosynthetic evolution in parasitic plants: insight from the chloroplast genome. Bioessays 26: 235-247. 
CAHOON, A.B. and STERN, D.B. (2001) Plastid transcription: a menage à trois ? Trends Plant Sci. 6: 45-46.

CAROL, P., STEVENSON, D., BISANZ, C., BREITENBACH, J., SANDMANN, G., MACHE, R., COUPLAND, G. and KUNTZ, M. (1999) Mutations in the Arabidopsis gene immutans cause a variegated phenotype by inactivating a chloroplast terminal oxidase associated with phytoene desaturation. Plant Cell 11: 57-68.

CHATTERJEE, M., SPARVOLI, S., EDMUNDS, C., GAROSI, P., FINDLAY, K. and MARTIN, C. (1996) DAG, a gene required for chloroplast differentiation and palisade development in Antirrhinum majus. EMBO J. 15: 4194-4207.

CHAVEZ-BARCENAS, A.T., VALDEZ-ALARCON, J.J., MARTINEZ-TRUJILLO, M., CHEN, L., XOCONOSTLE-CAZARES, B., LUCAS, W.J. and HERRERAESTRELLA, L. (2000) Tissue-specific and developmental pattern of expression of the rice sps1 gene. Plant Physiol. 124: 641-653.

CHORY, J. and PETO, C.A. (1990) Mutations in the DET1 gene affect cell-typespecific expression of light-regulated genes and chloroplast development in Arabidopsis. Proc. Natl. Acad. Sci. USA 87: 8776-8880.

CHUN, L., KAWAKAMI, A. and CHRISTOPHER, D.A. (2001) Phytochrome A mediates blue light and UV-A-dependent chloroplast gene transcription in green leaves. Plant Physiol. 125: 1957-1966.

COLLETTI, K.S., TATTERSALL, E.A., PYKE, K.A., FROELICH, J.E., STOKES, K.D. and OSTERYOUNG, K.W. (2000) A homologue of the bacterial cell division sitedetermining factor MinD mediates placement of the chloroplast division apparatus. Curr. Biol. 10: 507-516.

CONSTAN, D., PATEL, R., KEEGSTRA, K. and JARVIS, P. (2004) An outer envelope membrane component of the plastid protein import apparatus plays an essential role in Arabidopsis. Plant J. 38: 93-106.

COOKSON, P.J., KIANO, J.W., SHIPTON, C.A., FRASER, P.D., ROMER, S., SCHUCH, W., BRAMLEY, P.M. and PYKE, K.A. (2003) Increases in cell elongation, plastid compartment size and phytoene synthase activity underlie the phenotype of the high pigment-1mutant of tomato. Planta 217: 896-903.

DE LAS RIVAS, J., LOZANO, J.J. and ORTIZ, A.R. (2002) Comparative analysis of chloroplast genomes: functional annotation, genome-based phylogeny and deduced evolutionary patterns. Genome Res. 12: 567-583.

DUBELL, A.N. and MULLET, J.E. (1995a) Continuous far-red light activates plastid DNA-synthesis in pea leaves but not full cell enlargement or an increase in plastid number per cell. Plant Physiol. 109: 95-103.

DUBELL, A.N. and MULLET, J.E. (1995b) Differential transcription of pea chloroplast genes during light-induced leaf development transcription - Continuous far-red light activates chloroplast transcription. Plant Physiol. 109: 95-103.

DYALL, S.D., BROWN, M.T. and JOHNSON, P.J. (2004) Ancient invasions: From endosymbionts to organelles. Science 340: 253-257.

ELSEN, S., SWEM, L.R., SWEM, D.L. and BAUER, C.E. (2004) RegB/RegA, a highly conserved redox-responding global two-component regulatory system. Microbiol. Mol. Biol. Rev. 68: 263-279

EL-SHAMI, M., EL-KAFAFI, S., FALCONET, D. and LERBS-MACHE, S. (2002) Cell cycle-dependent modulation of Fts $Z$ expression in synchronized tobacco BY2 cells. Mol. Genet. Genom. 267: 254-261.

ESCOUBAS, J.M., LOMAS, M., LAROCHE, J. and FALKOWSKI, P.G. (1995) Lightintensity regulation of $C a b$ gene-transcription is signalled by the redox state of the plastoquinone pool. Proc. Natl. Acad. Sci. USA 92: 10237-10241.

ESTEVEZ, J.M., CANTERO, A., ROMERO, C., KAWAIDE, H., JIMENEZ, L.F., KUZUYAMA, T., SETO, H., KAMIYA, Y. and LEON, P. (2000) Analysis of the expression of CLA1, a gene that encodes the 1-deoxyxylulose 5-phosphate synthase of the 2-C-methyl-D-erythritol-4-phosphate pathway in Arabidopsis. Plant Physiol. 124: 95-103.

EWING, R.M., JENKINS, G.I. and LANGDALE, J.A. (1998) Transcripts of maize RbcS genes accumulate differentially in C-3 and C-4 tissues. Plant Mol. Biol. 36: 593599.

FANKHAUSER, C. (2001) The phytochromes, a family of red/far-red absorbing photoreceptors. J. Biol. Chem. 276: 11453-11456.

FERRO, M., SALVI, D., BRUGIĖRE, S., MIRAS, S., KOWALSKI, S., LOUWAGIE, M., GARIN, J., JOYARD, J. and ROLLAND, N. (2003) Proteomics of the chloroplast envelope membranes from Arabidopsis thaliana. Mol. Cel. Proteomics 2: 325345.

FITTER, D.W., MARTIN, D.J., COPLEY, M.J., SCOTLAND, R.W. and LANGDALE, J.A. (2002) GLK gene pairs regulate chloroplast development in diverse plant species. Plant J. 31: 713-727.

FLÜGGE, U.I. (2001) Plant chloroplasts and other plastids. In: Encyclopedia of Life Sciences, Macmillan, London / www.els.net

FUJIWARA, M., NAGASHIMA, A., KANAMARU, K., TANAKA, K. and TAKAHASHI, H. (2000) Three new nuclear genes, sigD, sigE and sig $F$, encoding putative plastid RNA polymerase sigma factors in Arabidopsis thaliana. FEBS Let. 481:47-52.

FUJIWARA, M.T., NAKAMURA, A., ITOH, R., SHIMADA, Y., YOSHIDA, S. and MØLLER, S.G. (2004) Chloroplast division site placement requires dimerization of the ARC11/AtMinD1 protein in Arabidopsis. J. Cell Sci. 117: 2399-2410.

FULGOSI, H., GERDES, L., WESTPHAL, S., GLOCKMANN, C. and SOLL, J. (2002) Cell and chloroplast division requires ARTEMIS. Proc. Natl. Acad. Sci. USA 99: 11501-11506.

GAO, H.B., KADIRJAN-KALBACH, D., FROEHLICH, J.E. and OSTERYOUNG, K.W. (2003) ARC5, a cytosolic dynamin-like protein from plants, is part of the chloroplast division machinery. Proc. Natl. Acad. Sci. USA 100: 4328-4333.

GIOVANNONI, J.J. (2004) Genetic regulation of fruit development and ripening. Plant Cell 16: S170-S180.

GOTO, S., NIWA, Y. and KOBAYASHI, H. (2004) Development into the functional chloroplast involves a receptor-like kinase in Golgi vesicles in Arabidopsis. In Proc. 13th Int. Cong. Photosynth. (in press)

GRAY, J.C., SULLIVAN, J.A., WANG, J.H., JEROME, C.A. and MACLEAN, D. (2002) Coordination of plastid and nuclear gene expression. Phil. Trans. R. Soc. Lond. B Biol. Sci. 358: 135-145.

GUTIERREZ-NAVA, M.D.L., GILLMOR, C.S., JIMENEZ, L.F., GUEVARA-GARCIA, A. and LEON, P. (2004) Chloroplast biogenesis genes act cell and noncell autonomously in early chloroplast development. Plant Physiol. 135: 471-482.

HASHIMOTO, H. and POSSINGHAM, J.V. (1989a) DNA levels in dividing and developing plastids in expanding leaves of Avena sativa. J. Exp. Bot. 40:257-262.

HASHIMOTO, H. and POSSINGHAM, J.V. (1989b) Effect of light on the chloroplast division cycle and DNA synthesis in cultured leaf discs of spinach. Plant Physiol. 89: 1178-1183.

HEDTKE, B., BORNER, T. and WEIHE, A. (1997) Mitochondrial and chloroplast phage-type RNA polymerases in Arabidopsis. Science 277: 809-811.

HEINS, L., MEHRLE, A., HEMMLER, R., WAGNER, R., KUCHLER, M., HORMANN, F., SVESHNIKOV, D. and SOLL, J. (2002) The preprotein conducting channel at the inner envelope membrane of plastids. EMBO J.21: 2616-2625.

HIBBERD, J.M. and QUICK, W.P. (2002) Characteristics of C-4 photosynthesis in stems and petioles of C-3 flowering plants. Nature 415: 451-454.

HILLS, A.C. (2002) Regulation of chloroplast biogenesis by light and plastid-viability signals. Ph.D. Thesis, University of London.

HUANG, C.Y., AYLIFFE, M.A. and TIMMIS, J.N. (2003) Direct measurement of the transfer rate of chloroplast DNA into the nucleus. Nature 422: 72-76.

HUBSCHMANN, T. and BORNER, T. (1998) Characterisation of transcript initiation sites in ribosome-deficient barley plastids. Plant Mol. Biol. 36: 493-496.

ISHIZAKI, Y., TSUNOYAMA, Y., HATANO, K., KOBORI, M., TAKEBA, G., NAKAHIRA, Y. and SHIINA, T. (2004) Arabidopsis Sig6 is a general sigma factor in chloroplasts, important for transcription of photosynthesis-related genes at an early stage of seedling growth. Plant Cell Physiol. 45: S33-S33.

ISONO, K., SHIMIZU, M., YOSHIMOTO, K., NIWA, Y., SATOH, K., YOKOTA, A. and KOBAYASHI, H. (1997) Leaf-specifically expressed genes for polypeptides destined for chloroplasts with domains of $\sigma^{70}$ factors of bacterial RNA polymerases in Arabidopsis thaliana. Proc. Natt. Acad. Sci. USA 94: 14948-14953.

ITOH, R., FUJIWARA, M., NAGATA, N. and YOSHIDA, S. (2001) A chloroplast protein homologous to the eubacterial topological specificity factor MinE plays a role in chloroplast division. Plant Physiol. 127: 1644-1655.

IVANOVA Y., SMITH, M.D., CHEN, K.H. and SCHNELL, D.J. (2004) Members of the Toc159 import receptor family represent distinct pathways for protein targeting to plastids. Mol. Biol. Cell 15: 3379-3392.

JACKSON-CONSTAN, D. and KEEGSTRA, K. (2001) Arabidopsis genes encoding components of the chloroplastic protein import apparatus. Plant Physiol. 125: 1567-1576.

JARVIS, P., CHEN, L.J., LI, H.M., PETO, C.A., FANKHAUSER, C. and CHORY, C. (1998) An Arabidopsis mutant defective in the plastid general protein import apparatus. Science 282: 100-103.

JARVIS, P., DORMANN, P., PETO, C.A., LUTES, J., GENNING, C. and CHORY, J. 
(2000) Galactolipid deficiency and abnormal chloroplast development in the Arabidopsis MGD synthase 1 mutant. Proc. Natl. Acad. Sci. USA. 97: 8175-8179.

JARVIS, P. and ROBINSON, C. (2004) Mechanisms of protein import and routing in chloroplasts. Curr. Biol. 14: R1064-R1077.

JASINSKI, S., LEITE, C.S., DOMENICHINI, D., STEVENS, R., RAYNAUD, C., PERENNES, C., BERGOUNIOUX, C. and GLAB, N. (2003) NtKIS2, a novel tobacco cyclin-dependent kinase inhibitor is differentially expressed during the cell cycle and plant development. Plant Physiol. Biochem. 41: 667-676.

JEONG, W.J., PARK, Y.I., SUH, K., RAVEN, J.A., YOO, O.J. and LIU, J.R. (2002) A large population of small chloroplasts in tobacco leaf cells allows more effective chloroplast movement than a few enlarged chloroplasts. Plant Physiol. 129: 112121.

KANAMARU, K., NAGASHIMA, A., FUJIWARA, M., SHIMADA, H., SHIRANO, Y., NAKABAYASHI, K., SHIBATA, D., TANAKA, K. and TAKAHASHI, H. (2001) An Arabidopsis sigma factor (SIG2)-dependent expression of plastid-encoded tRNAs in chloroplasts. Plant Cell Physiol. 42: 1034-1043.

KEDDIE, J.S., CARROLL, B., JONES, J.D.G. and GRUISSEM, W. (1996) The DCL gene of tomato is required for chloroplast development and palisade cell morphogenesis in leaves. EMBO. J. 15: 4208-4217.

KEEGSTRA, K. and FROEHLICH, J.E. (1999) Protein import into chloroplasts. Curr. Opin. Plant Biol. 2: 471-476.

KLEFFMANN, T., RUSSENBERGER, D., VON ZYCHLINSKI, A., CHRISTOPHER, W., SJÖLANDER, K., GRUISSEM, W. and BAGINSKY, S. (2004). The Arabidopsis thaliana chloroplast proteome reveals pathway abundance and novel protein functions. Curr. Biol. 14: 354-362.

KÖHLER, R.H., CAO, J., ZIPFEL, W.R., WEBB, W.W. and HANSON, M.R. (1997) Exchange of protein molecules through connections between higher plant plastids. Science 276: 2039-2042.

KOHLER, R.H. and HANSON, M.R. (2000) Plastid tubules of higher plants are tissuespecific and developmentally regulated. J. Cel/ Sci. 113: 3921-3930.

KOJIMA, K., SASAKI, S. and YAMAMOTO, N. (1994) Light-independent and tissuespecific expression of a reporter gene mediated by the pine Cab- 6 promoter in transgenic tobacco. Plant J. 6: 591-596.

KUBIS, S., BALDWIN, A., PATEL, R., RAZZAQ, A., DUPREE, P., LILLEY, K., KURTH, J., LEISTER, D. and JARVIS, P. (2003) The Arabidopsis ppi1 mutant is specifically defective in the expression, chloroplast import and accumulation of photosynthetic proteins. Plant Cel/ 15: 1859-1871.

KUBIS, S., PATEL, R., COMBE, J., BEDARD, J., KOVACHEVA, S., LILLEY, K., BIEHL, A., LEISTER, D., RIOS, G., KONCZ, C. and JARVIS, P. (2004) Functional specialization amongst the Arabidopsis Toc159 family of chloroplast protein import receptors. Plant Cel/ 16: 2059-2077.

KUMAR, S., DHINGRA, A. and DANIELL, H. (2004) Stable transformation of the cotton plastid genome and maternal inheritance of transgenes. PlantMol. Biol. 56: 203-216.

KUNO, N. and FURUYA, M. (2000) Phytochrome regulation of nuclear gene expression in plants. Semin. Cell Dev. Biol. 11: 485-493

KURODA, H. and MALIGA, P. (2003) The plastid $c / p P 1$ protease gene is essential for plant development. Nature 425: 86-89.

LA ROCCA, N., RASCIO, N., OSTER, U. and RUDIGER, W. (2001) Amitrole treatment of etiolated barley seedlings leads to deregulation of tetrapyrrole synthesis and to reduced expression of $L h c$ and RbcS genes. Planta 213: 101108.

LEISTER, D. (2003) Chloroplast research in the genomic age. Trends Genet. 19: 4756.

LEE, Y.J., KIM, D.H., KIM, Y.W. and HWANG, I. (2001) Identification of a signal that distinguishes between the chloroplast outer envelope membrane and the endomembrane system in vivo. Plant Cell 13: 2175-2190.

LI, H. and SHERMAN, L.A. (2000) A redox-responsive regulator of photosynthesis gene expression in the cyanobacterium Synechocystis sp strain PCC 6803. J. Bacteriol. 182: 4268-4277.

LIN, Y. and CHENG, C.L. (1997) A chlorate-resistant mutant defective in the regulation of nitrate reductase gene expression in Arabidopsis defines a new $H Y$ locus. Plant Cell 9: 21-35.

LJUBICIC, J.M., WRISCHER, M. and LJUBICIC, N. (1998) Formation of the photosynthetic apparatus in plastids during greening of potato microtubers. Plant Physiol.
Biochem. 36: 747-752

LOPEZ-JUEZ, E. and HUGHES, M. (1995) Effect of blue light and red light on the control of chloroplast acclimation of light-grown pea leaves to increased fluence rates. Photochem. Photobiol. 61: 106-111

LOPEZ-JUEZ, E., JARVIS, R.P., TAKEUCHI, A., PAGE, A. and CHORY, J. (1998). New Arabidopsis $C A B$-underexpressed (cue) mutants suggest a role for plastids in the regulation of nuclear gene expression by light. Plant Physiol. 118: 803-815

LOPEZ-JUEZ, E., STREATFIELD, S. and CHORY, J. (1996). Light signals and autoregulated chloroplast development. In W.R. Briggs, R.L. Heath and E.M. Tobin, (eds.) Lightregulation of Plant Development ASPP Symposium Series. Pp. 144-152

LURIN, C. ANDRES, C., AUBOURG, S., BELLAOUI, M., BITTON, F., BRUYERE, C., CABOCHE, M., DEBAST, C., GUALBERTO, J., HOFFMANN, B., LECHARNY, A., LE RET, M., MARTIN-MAGNIETTE, M.L., MIREAU, H., PEETERS, N., RENOU, J.P., SZUREK, B., TACONNAT, L. and SMALL, I. (2004) Genome-wide analysis of Arabidopsis pentatricopeptide repeat proteins reveals their essential role in organelle biogenesis. Plant Cell 16: 2089-2103.

MA, L., LI, J., QU, L., HAGER, J., CHEN, Z., ZHAO, H. and DENG, X.W. (2001) Light Control of Arabidopsis Development Entails Coordinated Regulation of Genome Expression and Cellular Pathways. Plant Cell 13: 2589-2607.

MACHE R. and LERBS-MACHE S. (2001) Chloroplast genetic system of higher plants: chromosome replication, chloroplast division and elements of the transcriptional apparatus. Current Sci. 80: 217-224.

MALIGA, P. (2003) Progress towards commercialization of plastid transformation technology. Trends Biotech. 21: 20-28.

MAPLE, J., CHUA, N.H. and MØLLER, S.G. (2002) The topological specificity factor AtMinE1 is essential for correct plastid division site placement in Arabidopsis. Plant J. 31: 269-277

MARANO, M.R. and CARRILLO, N. (1992) Constitutive transcription and stable RNA accumulation in plastids during the conversion of chloroplasts to chromoplasts in ripening tomato fruits. Plant Physiol. 100: 1103-1113.

MARRISON, J.L., RUTHERFORD, S.M., ROBERTSON, E.J., LISTER, C., DEAN, C and LEECH, R.M. (1999) The distinctive roles of five different $A R C$ genes in the chloroplast division process in Arabidopsis. Plant J. 18: 651-662.

MARTIN, W. and HERRMANN, R.G. (1998) Gene transfer from organelles to the nucleus: how much, what happens and why? Plant Physiol. 118: 9-17.

MARTIN, W.and KOWALLIK, K.V. (1999) Annotated English translation of Mereschkowsky's 1905 paper 'Uber Natur und Ursprung der Chromatophoren im Pflanzenreiche. Eur. J. Phycol. 34: 287-295.

MARTIN, W., RUJAN, T., RICHLY, E., HANSEN, A., CORNELSEN, S., LINS, T., LEISTER, D., STOEBE, B., HASEGAWA, M. and PENNY, D. (2002) Evolutionary analysis of Arabidopsis, cyanobacterial and chloroplast genomes reveals plastid phylogeny and thousands of cyanobacterial genes in the nucleus. Proc. Natl. Acad. Sci. USA 99: 12246-12251.

MARTINEZ-HERNANDEZ, A., LOPEZ-OCHOA, L., ARGUELLO-ASTORGA, G. and HERRERA-ESTRELLA, L. (2002) Functional properties and regulatory complexity of a minimal RBCS light-responsive unit activated by phytochrome, cryptochrome and plastid signals. Plant Physiol. 128: 1223-1233.

MAY, T. and SOLL, J. (2000) 14-3-3 proteins form a guidance complex with chloroplast precursor proteins in plants. Plant Cel/12: 53-63.

MAYFIELD, S.P. and TAYLOR, W.C. (1984) Carotenoid-dificient maize seedlings fail to accumulate light-harvesting chlorophyll a/b binding protein (LHCP) mRNA. Eur. J. Biochem. 144: 79-84

MCFADDEN, G.I. (1999) Endosymbiosis and evolution of the plant cell. Curr. Op. Plant Biol. 2: 513-519.

MINGO CASTEL, A.M., PELACHO, A.M. and DE FELIPE (1991) Amyloplast division in kinetin induced potato tubers. Plant Sci. 73: 211-217.

MIYAGISHIMA, S.Y., TAKAHARA, R. and KUROIWA, T. (2001) Novel filaments $5 \mathrm{~nm}$ in diameter constitute the cytosolic ring of the plastid division apparatus. Plant Cell 13: $707-721$.

MIYAZAWA, Y., SAKAI, A., MIYAGISHIMA, S.-Y. TAKANO, H., KAWANO, S. and KUROIWA, T. (1999) Auxin and cytokinin have opposite effects on amyloplast development and the expression of starch synthesis genes in cultured Bright Yellow-2 tobacco cells. Plant Physiol. 121: 461-469.

MOCHIZUKI, N., BRUSSLAN, J.A., LARKIN, R., NAGATANI, A. and CHORY, J. 
(2001) Arabidopsis genomes uncoupled 5 (GUN5) mutant reveals the involvement of $\mathrm{Mg}$-chelatase $\mathrm{H}$ subunit in plastid-to-nucleus signal transduction. Proc. Natl. Acad. Sci. USA 98: 2053-2058.

MOCHIZUKI, T., ONDA, Y., FUJIWARA, E., WADA, M. and TOYOSHIMA, Y. (2004) Two independent light signals cooperate in the activation of the plastid psbD blue light-responsive promoter in Arabidopsis. FEBS Lett. 571: 26-30.

MORITA, M.T. and TASAKA, M. (2004) Gravity sensing and signalling. Curr. Op. Plant Biol. 7: 712-718.

MULLET, J.E. (1993) Dynamic regulation of chloroplast transcription. Plant Physiol. 103: 309-313.

MUSTARDY, L. and GARAB, G. (2003) Granum revisited. A three-dimensional model - where things fall into place. Trends Plant Sci. 8: 117-122.

NAGASHIMA, A., HANAOKA, M., SHIKANAI, T., FUJIWARA, M., KANAMARU, K, TAKAHASHI, $H$. and TANAKA, K. (2004) The multiple-stress responsive plastid sigma factor, SIG5, directs activation of the psbD blue light-responsive promoter (BLRP) in Arabidopsis thaliana. Plant Cell Physiol. 45: 357-368.

NEUHAUS, H.E. and EMES, M.J. (2000) Nonphotosynthetic metabolism in plastids. Annu. Rev. Plant Physiol. Plant Mol. Biol. 51: 111-140.

OELMÜLLER, R., LEVITAN, I., BERGFELD, R., RAJASEKHAR, V.K. and MOHR, H. (1986) Expression of nuclear genes as affected by treatments acting on plastids. Planta 168: 482-492.

OGRZEWALLA, K., PIOTROWSKI, M., REINBOTHE, S. and LINK, G. (2002) The plastid transcription kinase from mustard (Sinapis alba L.) - A nuclear-encoded CK2-type chloroplast enzyme with redox-sensitive function. Eur. J. Biochem. 269: 3329-3337.

ORT, D.R. (2001) When there is too much light. Plant Physiol. 125: 29-32.

OSTERYOUNG, K.W. and NUNNARI, J. (2003) The division of endosymbiotic organelles. Science 302: 1698-1704.

OSTERYOUNG, K.W. and VIERLING, E. (1995) Conserved cell and organelle division. Nature 376: 473-474.

PELTIER, J.B., EMANUELSSON, O., KALUME, D.E., YTTERBERG, J., FRISO, G., RUDELLA, A., LIBERLES, D.A., SODERBERG, L., ROEPSTORFF, P., VON HEIJNE, G. and VAN VIJK, K.J. (2002) Central functions of the lumenal and peripheral thylakoid proteome of Arabidopsis determined by experimentation and genome-wide prediction. Plant Cell 14: 211-236.

PELTIER, J.B., YTTERBERG, A.J., SUN, Q. and VAN WIJK, K.J. (2004) New functions of the thylakoid membrane proteome of Arabidopsis thaliana revealed by a simple, fast and versatile fractionation strategy. J. Biol. Chem. 279: 4936749383

PFANNSCHMIDT, T. (2003) Chloroplast redox signals: how photosynthesis controls its own genes. Trends Plant Sci. 8: 33-41.

PFANNSCHMIDT, T., NILSSON, A. and ALLEN, J.F. (1999) Photosynthetic control of chloroplast gene expression. Nature 397: 625-628.

PIECHULLA, B., GLICK, R.E., BAHL, H., MELIS, A. and GRUISSEM, W. (1987) Changes in photosynthetic capacity and photosynthetic protein patterns during tomato fruit ripening. Plant Physiol. 84: 911-917.

POSSINGHAM J.V. and LAWRENCE, M.E. (1983) Controls to plastid division. Int. Rev. Cytol. 84: 1-56.

PRIVAT, I., HAKIMI, MA., BUHOT, L., FAVORY, J.J. and LERBS-MACHE, S. (2003) Characterization of Arabidopsis plastid sigma-like transcription factors SIG1, SIG2 and SIG3. Plant Mol. Biol. 51: 385-399.

PYKE, K.A. (1997) The genetic control of plastid division in higher plants. Am. J. Bot. 84: 1017-1027.

PYKE, K.A. (1999) Plastid division and development. Plant Cel/ 11: 549-556.

PYKE, K.A., MARRISON, J.L. and LEECH, R.M. (1991) Temporal and spatial development of the cells of the expanding 1st leaf of Arabidopsis thaliana (L) Heynh. J. Exp. Bot. 42: 1407-1416.

PYKE, K.A. and HOWELLS, C.A. (2002) Plastid and stromule morphogenesis in tomato. Ann. Bot.-London 90: 559-566.

PYKE, K.A. and LEECH, R.M. (1992) Chloroplast division and expansion is radically altered by nuclear mutations in Arabidopsis thaliana. Plant Physiol. 99: 10051008

PYKE, K.A. and LEECH, R.M. (1994) A genetic analysis of chloroplast division and expansion in Arabidopsis thaliana. Plant Physiol. 104: 201-207.
PYKE, K.A., RUTHERFORD, S.M., ROBERTSON, E.J. and LEECH, R.M. (1994) arc6, a fertile Arabidopsis mutant with only 2 mesophyll cell chloroplasts. Plant Physiol. 106: 1169-1177.

PYKE, K. and LOPEZ-JUEZ, E. (1999). Cellular differentiation and leaf morphogenesis in Arabidopsis. CRC Critical Reviews in Plant Science 18: 527-546

PYKE, K., ZUBKO, M.K. and DAY, A. (2000) Marking cell layers with spectinomycin provides a new tool for monitoring cell fate during leaf development. J. Exp. Bot. 351: 1713-1720.

RICHLY, E. and LEISTER, D. (2004) An improved prediction of chloroplast proteins reveals diversities and commonalities in the chloroplast proteomes of Arabidopsis and rice. Gene 329: 11-16.

ROBINSON, C., THOMPSON, S.J. and WOODHEAD, C. (2001) Multiple pathways used for the targeting of thylakoid proteins in chloroplasts. Traffic 2: 245-251.

RODERMEL, S. (2001) Pathways of plastid-to-nucleus signaling. Trends Plant Sci. 6 : 471-478.

RODRÍGUEZ-CONCEPCIÓN, M., AHUMADA, I., DIEZ-JUEZ, E., SAURET-GUETO, S., LOIS L.M., CARRETERO-PAULET, L., CAMPOS, N. and BORONAT, A. (2001) 1-Deoxy-D-xylulose 5-phosphate reductoisomerase and plastid isoprenoid biosynthesis during tomato fruit ripening. Plant J. 27: 213-222.

RODRÍGUEZ-CONCEPCIÓN, M. and BORONAT, A., (2002) Elucidation of the methylerythritol phosphate pathway for isoprenoid biosynthesis in bacteria and plastids. A metabolic milestone achieved through genomics. Plant Physiol. 130: 1079-1089.

ROSSINI, L., CRIBB, L., MARTIN, D.J. and LANGDALE, J.A. (2001) The maize Golden2 gene defines a novel class of transcriptional regulators in plants. Plant Cell 13: 1231-1244.

SAKAI, A., MIYAZAWA, Y., SUZUKI, T., SASAKI, N., KAWANO, S. and KUROIWA, T. (1999) Plastid gene expression during amyloplast formation in cultured tobacco cells. J. Plant Physiol. 154: 71-78.

SAKAI, T., KAGAWA, T., KASAHARA, M., SWARTZ, T.E., CHRISTIE, J.M., BRIGGS, W.R., WADA, M. and OKADA, K. (2001) Arabidopsis nph1 and npl1: Blue light receptors that mediate both phototropism and chloroplast relocation. Proc. Natt. Acad. Sci. USA 98: 6969-6974.

SAKAMOTO, W. (2003) Leaf-variegated mutations and their responsible genes in Arabidopsis thaliana. Genes Genet. Syst. 78: 1-9.

SAKAMOTO, W., ZALTSMAN, A., ADAM, Z. and TAKAHASHI, Y. (2003) Coordinated regulation and complex formation of YELLOW VARIEGATED1 and YELLOW VARIEGATED2, chloroplastic FtsH metalloproteases involved in the repair cycle of photosystem II in Arabidopsis thylakoid membranes. Plant Cel/ 15: 2843-2855.

SATO, N., TERASAWA, K., MIYAJIMA, K. and KABEYA, Y. (2003) Organization, developmental dynamics and evolution of plastid nucleoids. Internat. Rev. Cytol. 232: 217-262

SAWBRIDGE, T.I., LOPEZ-JUEZ, E., KNIGHT, M.R. and JENKINS, G.I. (1994). A blue-light photoreceptor mediates the fluence rate-dependant control of $r b c S$ gene expression in light grown Phaseo/us vulgaris primary leaves. Planta 192: $1-8$

SCHAFER, E. and BOWLER, C. (2002) Phytochrome-mediated photoperception and signal transduction in higher plants. EMBO Rep. 3: 1042-1048.

SCHLEIFF, E., SOLL, J., KUCHLER, M., KUHLBRANDT, W. and HARRER, R. (2003) Characterizaation of the translocon of the outer envelope of chloroplasts. J. Cell Biol. 160: 541-551.

SHIMADA, H., KOIZUMI, M., KUROKI, K., MOCHIZUKI, M., FUJIMOTO, H., OHTA, H., MASUDA, T. and TAKAMIYA, K. (2004) ARC3, a chloroplast division factor, is a chimera of prokaryotic FtsZ and part of eukaryotic phosphatidylinositol-4phosphate 5-kinase. Plant Cell Physiol. 45: 960-967.

SOLL, J. (2002) Protein import into chloroplasts. Curr. Op. Plant Biol. 5: 529-535.

STAEHLIN, L.A. and NEWCOMB, E.H. (2000) Membrane structure and membranous organelles. In Buchanan, B.B., Gruissem, W. and Jones, R.L. (eds.) Biochemistry and molecular biology of plants. ASPP. Rockville, Pp. 2-50.

STERN, D.B., HANSON, M.R. and BARKAN, A. (2004) Genetics and genomics of chloroplast biogenesis: maize as a model system. Trends Plant Sci. 9: 293-301.

STOCK, A.M., ROBINSON, V.L. and GOUDREAU, P.N. (2000) Two-component signal transduction. Annu. Rev. Biochem. 69: 183-215.

STRAND, Å (2004) Plastid-to-nucleus signalling. Curr. Op. Plant Biol. 7: 621-625.

STRAND, A, ASAMI, T., ALONSON, J., ECKER, J.R. and CHORY, J. (2003) 
Chloroplast to nucleus communication triggered by accumulation of $\mathrm{Mg}$ protoporphyrinIX. Nature 421: 79-83.

SUGIURA, M. (1992) The chloroplast genome. Plant Mol. Biol. 19: 149-168.

SUGIURA, M. (2003) History of chloroplast genomics. Photosynth. Res. 76: 371-377.

SUN, Y.J., FOROUHAR, F., LI, H.M., TU, S.L., YEH, Y.H., KAO, S., SHR, H.L., CHOU, C.C., CHEN, C.P. and HSIAO, C.D. (2002) Crystal structure of pea Toc34, a novel GTPase of the chloroplast protein translocon. Nature Stuct. Biol. 9: 95-100.

SURPIN, M., LARKIN, R.M. and CHORY, J. (2002) Signal transduction between the chloroplast and the nucleus. Plant Cell S327-S338

SUSEK, R.E., AUSUBEL, F.M. and CHORY, J. (1993) Signal transduction mutants of Arabidopsis uncouple nuclear $C A B$ and $R B C S$ gene expression from chloroplast development. Cell 74: 787-799.

SUZUKI J.Y., YTTERBERG, A.J., BEARDSLEE, T.A., ALLISON, J.A., VAN WIJK, K.J. and MALIGA, P. (2004) Affinity purification of the tobacco plastid RNA polymerase and in vitro reconstitution of the holoenzyme. Plant J. 40: 164-172.

TEPPERMAN, J.M., ZHU, T., CHANG, H.S., WANG, X. and QUAIL, P.H. (2001) Multiple transcription-factor genes are early targets of phytochrome A signalling. Proc. Natl. Acad. Sci. USA 98: 9437-9442.

THE RICE CHROMOSOME 10 SEQUENCING CONSORTIUM (2003) In-depth view of structure, activity and evolution of rice chromosome 10. Science 300: 15661569.

THUM, K.E., KIM, M., CHRISTOPHER, D.A. and MULLET, J.E. (2001) Cryptochrome 1 , chryptochrome 2 and phytochrome $A$ co-activate the chloroplast $p s b D$ lightresponsive promoter. Plant Cell 13: 2747-2760.

TIMMIS, J.N., AYLIFFE, M.A., HUANG, C.Y. and MARTIN, W. (2004) Endosymtiotic gene transfer: organelle genomes forge eukaryotic chromosomes. Nature Rev. Genet. 5: 123-136.

TSUNOYAMA, Y., ISHIZAKI, Y., MORIKAWA, K., KOBORI, M., NAKAHIRA, Y., TAKEBA, G., TOYOSHIMA, Y. and SHIINA, T. (2004) Blue light-induced transcription of plastid-encoded $p s b D$ gene is mediated by a nuclear-encoded transcription initiation factor, AtSig5. Proc. Natl. Acad. Sci. USA 101:3304-3309.

ULLANAT, R. and JAYABASKARAN, C. (2002) Light- and cytokinin-regulated fts $Z$ gene expression in excised cucumber cotyledons (Cucumis sativus). Plant Growth Reg. 38: 209-218.

VINTI, G., HILLS, A., CAMPBELL, S., BOWYER, J.R., MOCHIZUKI, N., CHORY, J. and LOPEZ-JUEZ, E. (2000). Interactions between hy1 and gun mutants of Arabidopsis and their implications for plastid/nuclear signalling. Plant J. 24: 883894

VINTI, G., FOURRIER, N., BOWYER, J.R. and LOPEZ-JUEZ, E. (2005). Arabidopsis cue mutants with defective plastids are impaired primarily in the photocontrol of expression of photosynthesis-associated nuclear genes. Plant Mol. Biol. 57: 343357.
VITHA, S., FROEHLICH, J.E., KOKSHAROVA, O., PYKE, K.A., VAN ERP, H. and OSTERYOUNG, K.W. (2003) ARC6 is a J-domain plastid division protein and an evolutionary descendant of the cyanobacterial cell division protein Ftn2. Plant Cell 15: 1918-1933.

VOGELMANN, T.C. (2002) Photosynthesis: physiological and ecological considerations. In Taiz, L. and Zeiger, E. (eds.) Plant Physiology. Sinauer, Sunderland, Pp. 171-192.

WALTERS, R.G. and HORTON, P. (1994) Acclimation of Arabidopsis thaliana to the light environment - Changes in composition of the photosynthetic apparatus. Planta 195: 248-256.

WALTERS, R.G., SHEPHARD, F., ROGERS, J.J.M., ROLFE, S.A. and HORTON, P. (2003) Identification of mutants of Arabidopsis defective in acclimation of photosynthesis to the light environment. Plant Physiol. 131: 472-481.

WAKASUGI, T., TSUDZUKI, T. and SUGIURA, M. (2001) The genomics of land plant chloroplasts: Gene content and alteration of genomic information by RNA editing Photosynth. Res. 70: 107-118.

WAN, J.X., BLAKELEY, S.D., DENNIS, D.T. and KO, K. (1996) Transit peptides play a major role in the preferential import of proteins into leucoplasts and chloroplasts. J. Biol. Chem. 271: 31227-31233.

WANG, H.Y. and DENG, X.W. (2003) Dissecting the phytochrome A-dependent signaling network in higher plants. Trends Plant Sci. 8: 172-178.

WATERS, M.T., FRAY, R.G. and PYKE, K.A. (2004) Stromule formation is dependent upon plastid size, plastid differentiation status and the density of plastids within the cell. Plant J. 39: 655-667.

WATERS, M. and PYKE, K. (2004) Plastid development and differentiation. In Møller, S.G. (ed.) Plastids. Blackwell, Oxford. Pp. 30-59.

WEIHE, A. and BÖRNER, T. (1999) Transcription and the architecture of promoters in chloroplasts. Trends Plant Sci. 4: 169-170.

WESTON, E.L. and PYKE, K.A. (1999) Developmental ultrastructure of cells and plastids in the petals of wallflower (Erysimum cheiri). Ann. Bot.-London 84: 763769.

WESTON, E., THOROGOOD, K., VINTI, G. and LOPEZ-JUEZ, E. (2000) Light quantity controls leaf-cell and chloroplast development in Arabidopsis thaliana wild type and blue light-perception mutants. Planta 211: 807-815.

WILLIS K.J. and MACELWAIN, J.C. (2002) The evolution of plants. Oxford Univ. Press, Oxford.

YU, T.S. and LI, H.M. (2001) Chloroplast protein translocon components atToc159 and atToc33 are not essential for chloroplast biogenesis in guard cells and root cells. Plant Physiol. 127: 90-96.

ZHANG, J., SCHNEIDER, C., OTTMERS, L., RODRIGUEZ, R., DAY, A., MARKWARDT, J. and SCHNEIDER, B.L. (2002) Genomic scale mutant hunt identifies cell size homeostasis genes in S. cerevisiae. Curr. Biol. 12: 1992-2001. 